\title{
Modelo estatístico de distribuição do volume de água aplicado por emissores na avaliação do desempenho do sistema de irrigação por gotejamento na cultura do maracujá
}

Statistical model of distribution of water volume applied by emitters in evaluating the performance of the drip irrigation system in the passion fruit crop

Modelo estadístico de distribución del volumen de agua aplicado por emisores en la evaluación del desempeño del sistema de riego por goteo en el cultivo de maracuyá

Recebido: 27/05/2021 | Revisado: 03/06/2021 | Aceito: 09/06/2021 | Publicado: 23/06/2021

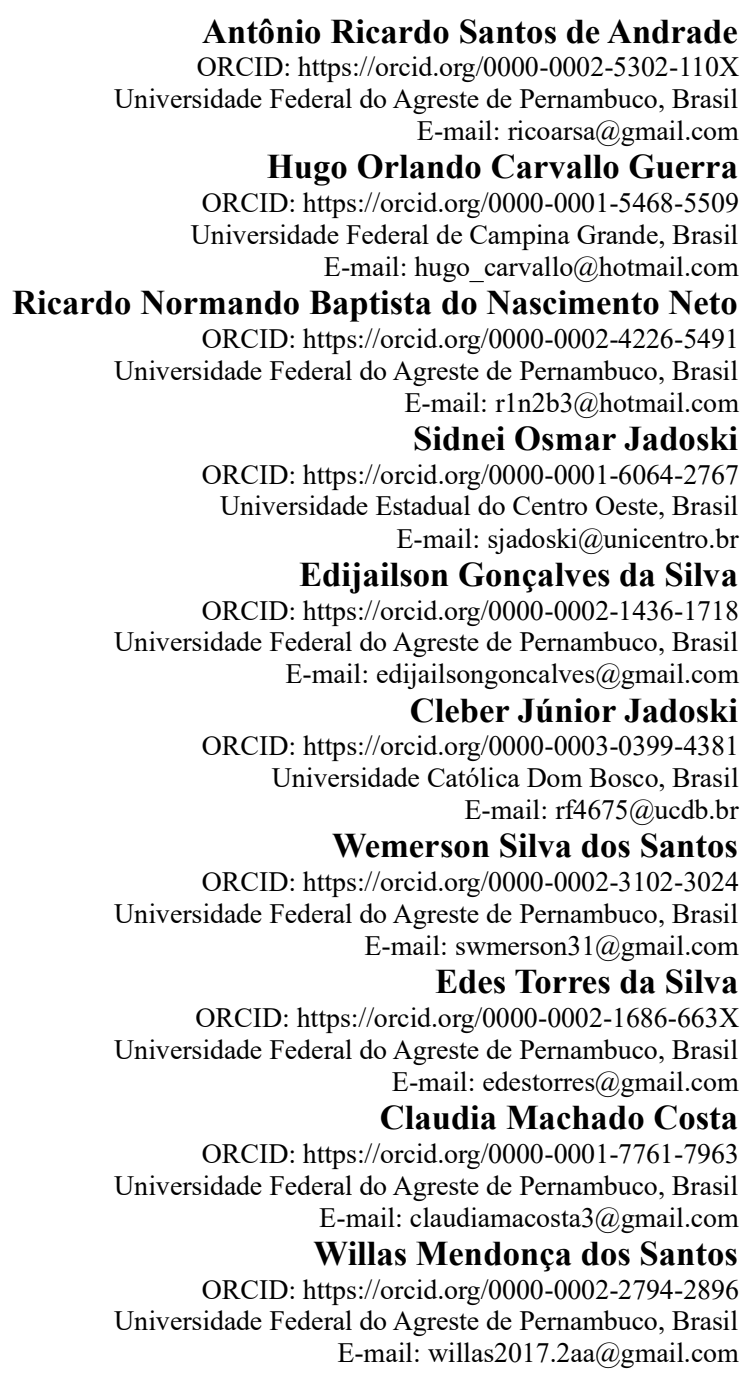

\section{Resumo}

O objetivo do trabalho foi avaliar o desempenho de um sistema de irrigação localizada, do tipo gotejamento, no cultivo do maracujázeiro, determinado a eficiência de aplicação de água por meio de modelos matemáticos e probabilísticos. $\mathrm{O}$ trabalho foi conduzido na Fazenda Areião, área experimental da ESALQ/USP, Piracicaba/SP. A avaliação da eficiência do sistema de irrigação com base nos dados de distribuição de volume de água obtidos nos testes realizado em campo,baseou-se nos seguintes parâmetros de desempenho: eficiência de aplicação de água (Ea), eficiência de armazenamento (Es), percolação profunda (Pp), percentagem de déficit $(\mathrm{Gd})$ e grau de adequação da irrigação (Gad). Para a avaliação desses parâmetros e da eficiência do sistema de irrigação, três diferentes metodologias foram utilizadas 
com base em procedimentos de modelagem matemática e estatística: a primeira metodologia é baseada nas expressões matemáticas segundo o Modelo Matemática Padrão (MMP), a segunda e a terceiro metodologias propostas por este estudo baseiam-se no procedimento estatístico utilizando o Modelo de Regressão não Linear (MRLN) e o Modelo Probabilístico não Linear (MPNL). Os resultados mostraram que não foram observadas diferenças entre os três modelos propostos como indicativos de medidas de eficiência de aplicação de água da irrigação, concluindo também que o sistema de irrigação em estudo encontra-se em perfeitas condições de operação. No entanto, os melhores resultados de eficiência média de armazenamento foram obtidos por meio do modelo estatístico do ajuste do polinômio do terceiro grau, com valor de $99,88 \%$.

Palavras-chave: Eficiência do uso da água; Irrigação localizada; Vazão; Passiflora sp.

\begin{abstract}
The objective of the study was to evaluate the performance of a local drip irrigation system in the cultivation of the passion fruit tree, determined the efficiency of water application through mathematical and probabilistic models. The study was conducted at Fazenda Areião, an experimental area of ESALQ/USP, Piracicaba/SP. The evaluation of the efficiency of the irrigation system based on the water volume distribution data obtained from the field tests was based on the following performance parameters: water application efficiency (Ea), storage efficiency (Es), deep percolation $(\mathrm{Pp})$, percentage deficit $(\mathrm{Gd})$ and degree of irrigation adequacy $(\mathrm{Gad})$. For the evaluation of these parameters and the efficiency of the irrigation system, three different methodologies were used based on mathematical and statistical modeling procedures: the first methodology is based on mathematical expressions according to the Standard Mathematical Model (MMP), the second and third methodologies proposed by this study are based on the statistical procedure using the Nonlinear Regression Model (MRLN) and the Nonlinear Probabilistic Model (MPNL). The results showed that no differences were observed between the three models proposed as indicative of measures of efficiency of irrigation water application, also concluding that the irrigation system under study is in perfect operating conditions. However, the best results of average storage efficiency were obtained by means of the statistical model of third-degree polynomial adjustment, with a value of $99.88 \%$.
\end{abstract}

Keywords: Water use efficiency; Localized irrigation; Flow rate; Passiflora sp.

\title{
Resumen
}

El objetivo del trabajo fue evaluar el desempeño de un sistema de riego localizado, del tipo goteo, en el cultivo del maracujázeiro, determinado la eficiencia de aplicación de agua por medio de modelos matemáticos y probabilísticos. El trabajo fue realizado en la Hacienda Areião, área experimental de la ESALQ/USP, Piracicaba/SP. La evaluación de la eficiencia del sistema de riego sobre la base de los datos de distribución del volumen de agua obtenidos en las pruebas realizadas en campo se basó en los siguientes parámetros de rendimiento: eficiencia de aplicación de agua (Ea), eficiencia de almacenamiento (Es), percolación profunda (Pp), porcentaje de déficit (Gd) y grado de adecuación de la irrigación (Gad). Para la evaluación de estos parámetros y de la eficiencia del sistema de riego, tres metodologías diferentes fueron utilizadas con base en procedimientos de modelado matemático y estadístico: la primera metodología es basada en las expresiones matemáticas según el Modelo Matemático Estándar (MMP), la segunda y la tercera metodologías propuestas por este estudio se basan en el procedimiento estadístico utilizando el Modelo de Regresión no Lineal (MRLN) y el Modelo Probabilístico no Lineal (MPNL). Los resultados mostraron que no se observaron diferencias entre los tres modelos propuestos como indicativos de medidas de eficiencia de aplicación de agua de riego, concluyendo también que el sistema de riego en estudio se encuentra en perfectas condiciones de operación. Sin embargo, los mejores resultados de eficiencia promedio de almacenamiento fueron obtenidos por medio del modelo estadístico del ajuste del polinomio del tercer grado, con valor de 99,88\%.

Palabras clave: Eficiencia del uso del agua; Irrigación localizada; Flujo; Pasiflora sp.

\section{Introdução}

Dentre os sistemas de irrigação utilizados nas atividades agrícolas, a irrigação por gotejamento tem-se destacado principalmente pela alta uniformidade de aplicação de água, alcançando assim alta eficiência de aplicação. Além de otimizar o uso da água e proporcionar inúmeras vantagens, tende a substituir os outros métodos de irrigação em certas situações, devido à notável economia de água proporcionada e à alta eficiência de aplicação de água, capaz de reduzir as perdas de água (Salomão, 2012; Cordão, 2019).

Na escolha de um método de irrigação, além de todos os fatores de seleção do próprio sistema e método em si, devem ser tomadas como base os parâmetros de uniformidade que estão relacionados à engenharia hidráulica do sistema e, principalmente, os parâmetros da eficiência de aplicação de água do sistema na qual envolve aspectos agronômicos da cultura (Oliveira, 2014, Alves et al., 2015). A eficiência de irrigação é um conceito amplamente utilizado, tanto em projetos quanto no 
manejo de sistemas de irrigação. De acordo com Souza et al. (2006), o conceito de eficiência engloba dois aspectos básicos: a uniformidade de aplicação e perdas, que podem ocorrer durante a operação do sistema. De acordo com Lima et al. (2012), os parâmetros de eficiência expressam a qualidade da irrigação e, ao mesmo tempo, incorporam alguns parâmetros da uniformidade, o que expressa a variabilidade do volume de aplicação de água pelos emissores na superfície do solo, onde a eficiência de aplicação de água depende tanto da uniformidade e de fatores puramente agronômicos, como quantidade e frequência de irrigação, características físicas do solo, profundidade radicular, superfície molhada e permeabilidade do solo.

Segundo Silva et al. (2004) a performance da irrigação pode ser determinado por paramentos de eficiência de aplicação de água pelo sistema de irrigação (Ea), eficiência de armazenamento (Es), percolação profunda (Pp), percentagem de déficit $(\mathrm{Gd})$ e Grau de adequação da irrigação (Gad). Quando esses parâmetros ou indicadores quando são maiores ou iguais a determinado valor arbitrário, o desempenho da água aplicada pelos emissores é considerada aceitável (Fernandes et al., 2015). Estes indicadores de desempenho podem ser obtidos de modelos matemáticos e estatísticos ajustados diretamente a partir dos valores pontuais de lâminas ou vazões coletados pelos emissores, permitindo a aplicação de expressões para o cálculo de áreas e volumes, fundamentais na determinação dos parâmetros de desempenho de sistemas de irrigação (Júnior et al., 2016).

A análise da distribuição espacial da água aplicada em áreas irrigadas é essencial na implementação de estratégias adequadas ao manejo da irrigação. Para isso, é imprescindível a utilização de modelos estatísticos e matemáticos, ajustados aos valores de lâminas ou vazões coletadas, no cálculo dos parâmetros de uniformidade e de eficiência da água aplicada por irrigação (Silva et al., 2006). Sob essa abordagem, o emprego, de modelos têm sido utilizados para representar a distribuição dos valores de lâmina de água aplicada em uma área irrigada, fundamental na avaliação do desempenho de sistemas de irrigação. Apesar dos avanços, ainda não existe um modelo universalmente aceito para a descrição da distribuição dos valores de água desses sistemas (Silva et al., 2004).

Diversos modelos matemáticos e estatísticos tem sido alvo de estudos, buscando o melhor ajuste dos valores pontuais de lâminas ou vazões coletados, obtidos na avaliação de desempenho de sistemas de irrigação com propósitos para descrever a distribuição da água aplicada por diversos sistemas de irrigação sob ótica de modelagem matemática com base nas estatísticas de distribuição de frequência: uniforme, normal, lognormal, potencial, beta e gama (Elliot et al., 1980; Anyoji \& Wu, 1994; Ailliot \& Monbet, 2012; Harrell, 2015). O modelo de distribuição estatística Beta foi reconhecido por Elliot et al. (1980) como sendo bastante flexível para descrever uma ampla variedade de perfis de distribuição de água da irrigação por aspersão (Silva et al., 2004; Silva et al., 2006). Neste contexto, o presente trabalho teve como objetivo estudar, por meio de ensaio em campo, os parâmetros de avaliação da eficiência de aplicação de água de um sistema de irrigação localizada, do tipo gotejamento, em cultivo de maracujá, utilizando modelos matemáticos e estatísticos, Modelo de Regressão não Linear (MRLN) e do Modelo Probabilístico não Linear (MPNL) que podem gerar melhores resultados quando comparados com medições diretas com os dados obtidos em campo por meio do Modelo Matemática Padrão (MMP).

\section{Material e Métodos}

\section{Caracterização da área experimental}

A avaliação do sistema de irrigação por gotejamento foi conduzida na Fazenda Areião, área experimental da ESALQ/USP, Piracicaba, SP. A fazenda está localizada no município de Piracicaba, São Paulo, cujas coordenadas geográficas são $22^{\circ} 42^{\prime} 30^{\prime \prime} \mathrm{S}$ de latitude, 47³8'00" W de longitude e altitude $576 \mathrm{~m}$. O clima, segundo classificação de Köppen, é do tipo Cwa, ou seja, clima subtropical úmido com estiagem no inverno, com precipitação pluviométrica média de $1247 \mathrm{~mm}$, temperatura de $21,1^{\circ} \mathrm{C}$ e umidade relativa média de $74 \%$, velocidade do vento de $2,2 \mathrm{~m} \mathrm{~s}^{-1}$. O solo da área onde se encontra o sistema de irrigação localizada é classificado como Terra Roxa Estruturada (Alfisol), com uma declividade média de 2,3. A área total irrigada é de $3.024 \mathrm{~m}^{2}$, sendo que a unidade operacional de $1.512 \mathrm{~m}^{2}$ é constituída por 12 linhas laterais, com espaçamento de 
3,5 m e 108 plantas distribuídas nessas 12 linhas (9 plantas por linha). Ao longo da linha lateral havia nove pontos de emissão, cada um com dois emissores separados $0,5 \mathrm{~m}$ um do outro. A cultura instalada no campo experimental foi o maracujá, com dois emissores por planta (ponto de emissão) cujas plantas apresentam o espaçamento de 3,5 x 4 m entre fileiras e entre plantas na mesma fileira, respectivamente.

\section{Determinação da uniformidade do sistema de irrigação}

Para avaliação da uniformidade de distribuição de água aplicada do sistema de irrigação por gotejamento, foi utilizado seguindo a metodologia de Keller e Karmeli (1975) recomendam que a coleta das vazões em quatro emissores ao longo de quatro linhas laterais. Em cada ponto de emissão foram determinadas as vazões de água dos emissores cujo tempo estabelecido para coleta foi de 5 min determinado com auxílio de um cronômetro de precisão e de uma proveta graduada em mL e a vazão de cada emissor foi de $40 \mathrm{~cm}^{3} \mathrm{~min}^{-1}\left(2,40 \mathrm{Lh}^{-1}\right)$ sob uma pressão de serviço de 10 mca. O coeficiente de variação de fabricação (CVF) tipo auto-compensante e marca carborundum foi de $5 \%$.

A vazão ou volume de aplicação de água pelos emissores (Va) foi determinada pelo método volumétrico, que segundo Salomão (2008), utilizando a Equação 1:

$\mathrm{Q}=\mathrm{Va}=(\mathrm{Vc} / 1000) /(\mathrm{t} / 60)$

Em que $\mathrm{Q}=\mathrm{V}_{\mathrm{a}}$ = vazão ou volume de aplicação de água pelos emissores $\left(\mathrm{Lh}^{-1}\right) ; \mathrm{V}_{\mathrm{c}}=$ volume de água coletado pelos emissores $(\mathrm{mL})$ e $\mathrm{t}=$ tempo de coleta em (min).

A partir da soma dos valores de vazão de água dos dois emissores por planta distribuídos em quatro tubulações laterais (ponto de emissão) na unidade operacional em estudo, foram obtidos os valores totais da vazão de água por ponto de emissão. Estes valores foram a base para a determinação dos parâmetros de avaliação da eficiência do sistema de irrigação localizada, tipo gotejamento, no cultivo de maracujá: eficiência de aplicação de água (Ea), eficiência de armazenamento (Es), percolação profunda (Pp), percentagem de déficit (Gd) e Grau de adequação da irrigação (Gad).

\section{Cálculo dos parâmetro da eficiência de aplicação de água pelo sistema de irrigação}

Os parâmetros de avaliação da eficiência da aplicação de água de irrigação por gotejamento foram determinados por meio de três diferentes metodologias: o primeiro Modelo Matemática Padrão (MMP) (ASAE, 1996) baseado em expressões matemáticas, e a segunda e a terceira metodologias baseadas em procedimentos estatísticos utilizando o Modelo de Regressão não Linear (MRLN) (Warrick, 1983; Silva et al., 2006; Mantovani et al., 2009) e do Modelo Probabilístico não Linear (MPNL) (Anyoji \& Wu, 1994; Wu, 1995; Silva et al., 2004), que utiliza a equação polinomial e a função de distribuição de probabilidade acumulativa da normal, respectivamente, ajustados aos valores das vazões ou volumes de água coletados dos emissores $\left(\mathrm{V}_{\mathrm{c}}\right)$. Esses volumes estão associados à área que cada coletor representa em relação à área total avaliada, é denominado de percentual ou fração da área irrigada acumulativa $\left(\mathrm{F}_{\mathrm{ac}}\right)$. Esta associação de área acumulativa varia de 0 a 1 e é adimensional.

Para avaliação do sistema de irrigação por gotejamento, foram utilizados dois emissores por planta, no total foram 36 coletores, conforme metodologia de Keller e Karmeli (1975) visando a avaliação da eficiência de água aplicada pelo sistema de irrigação, de forma que cada coletor representa uma fração de área correspondente 1/36 da área avaliada, ou seja, 0,027 (0,27 \% da área molhada). $\mathrm{O}$ volume de água dos emissores foi coletado com auxílio de 36 recipientes coletores (copos) posicionados abaixo dos gotejadores, apoiados em suporte de madeira, o qual teve como objetivo permitir o manuseio de todos os copos de uma vez, fazendo com que todos os emissores das linhas avaliadas fossem coletados em conjunto, a fim de evitar possíveis erros 
na estabilização e medição da pressão desejada. Os volumes de água coletadas foram medidos com o auxílio de uma proveta de plástico de volume de $100 \mathrm{~mL}$ graduada com precisão de $2 \mathrm{~mL}$ e um cronômetro.

a) Modelo matemático padrão ou tradicional (MMP) por meio de expressões matemáticas propostos por ABNT (1985) e ASAE (1996)

A avaliação da eficiência do sistema de irrigação localizada foi conduzida de acordo aos métodos tradicionais recomendados por Bernardo et al. (2006) e Mantovani et al. (2009).

\section{b) Metodologia baseada na modelagem probabilística}

Para realizar a modelagem probabilística da lâmina ou volume de água aplicado pelos emissores $\left(\mathrm{V}_{\mathrm{c}}\right)$, foram seguidas as metodologias propostas por Karmeli (1978), Warrick, (1983), Wu (1988), Warrick et al. (1989), Anyoji e Wu (1994), Silva et al. (2004) e Silva et al. (2006), que sugere ajustar o perfil de água aplicada pelo equipamento de irrigação às distribuições teóricas de probabilidades. Para a aplicação da modelagem probabilística aos dados de volume de água coletado pelos emissores $\left(\mathrm{V}_{c}\right)$ coletados peles gotejamentos, foram feitos ajustes da função de densidade de distribuição de probabilidade acumulada da normal ( $\left.\mathrm{FDP}_{\text {normal }}\right)$ e função de densidade de distribuição cumulativa corresponde a função polinomial ( $\mathrm{FP}_{\text {Acumulada }}$ ) aos valores de $\mathrm{V}_{\mathrm{c}}$ em função dos percentuais ou fração acumulada da área irrigada $\left(\mathrm{F}_{\mathrm{ac}}\right)$, conforme metodologias propostas por Karmeli (1978), Warrick, (1983), Wu (1988), Warrick et al. (1989), Anyoji e Wu (1994), Silva et al. (2004) e Silva et al. (2006), que sugere ajustar o perfil de água aplicada pelo equipamento de irrigação às distribuições teóricas de probabilidades.

Modelo probabilístico não linear (MPNL) baseia na função de distribuição de probabilidade acumulada da normal (FDP normal) $_{\text {) }}$ proposto por Anyoji e Wu (1994)

O modelo probabilístico proposto no estudo baseia-se na distribuição contínua mais importante e mais utilizada, que é a distribuição normal, geralmente denominada curva normal ou curva de Gaussiana. Sua importância em análise matemática decorre do fato de que muitas técnicas estatísticas, como análise de variância, de regressão e alguns testes de hipótese, pressupõem e exigem a normalidade dos dados. A função normal é a distribuição de dois parâmetros e tem a forma de um sino. Sua função de densidade de probabilidade, $\mathrm{f}(\mathrm{x})$, tem a seguinte forma:

$f(X)=\frac{1}{\sigma \sqrt{2 \pi}} e^{-\frac{(X-\mu)^{2}}{2 \sigma^{2}}}$

onde $\boldsymbol{\mu}=$ média, $\boldsymbol{\sigma}=$ desvio-padrão e $\mathbf{X}=$ variável aleatória contínua que, em nosso caso, seria a fração ou percentagem de área acumulada, que representa a frequência de ocorrência de cada vazão ou volume de água coletado pelos emissores obtidos de testes realizados em campo $\left(\mathrm{V}_{\mathrm{c}}, \mathrm{mL}\right)$.

Segundo Faccioli (2002), a distribuição normal acumulada pode ser utilizada para descrever a uniformidade de distribuição e a eficiência de aplicação de água, e para caracterizar os padrões de volume de água aplicados pelos emissores. O

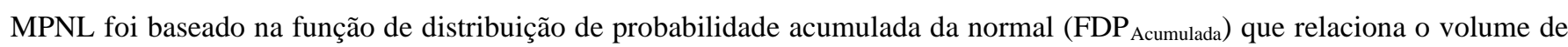
água coletada pelos emissores no campo $\left(\mathrm{Y}=\mathrm{V}_{\mathrm{c}}\right)$ em função da fração da área irrigada que recebeu o volume de água aplicados pelos emissores $\left(\mathrm{X}=\mathrm{F}_{\mathrm{ac}}\right.$ ), através de uma função de densidade de probabilidade acumulada da normal, $\mathrm{F}(\mathrm{X})$, Equação 3. O valor de $\mathrm{X}$ corresponde ao percentual ou da fração acumulativa da área irrigada que recebeu o $\mathrm{V}_{\mathrm{a}}$. A probabilidade acumulada de "X" assume valores menores ou iguais a um " $\mathrm{x}$ ”, quando $\mathrm{X}$ segue um distribuição normal com $\mathrm{N} \sim\left(\mu, \sigma^{2}\right)$ é estimada por: 
$P(X \leq x)=F(X)=\frac{1}{\sigma \sqrt{2 \pi}} \int_{-\infty}^{x} e^{-\frac{(X-\mu)^{2}}{2 \sigma^{2}}} d X$

Onde $\mathrm{F}(\mathrm{X})$ representa a função de densidade de distribuição de probabilidade acumulada para a distribuição normal

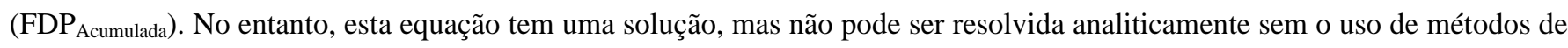
integração aproximada. Por esta motivo, usa-se a transformação $\mathrm{Z}=(\mathrm{X}-\mu) / \sigma$ e, portanto, a variável $\mathrm{Z}$ tem distribuição normal com $\mathrm{N} \sim(0,1)$. Onde $\mathrm{Z}$ é denominada de variável reduzida e $\mathrm{F}(\mathrm{Z})$ é denominada de função de distribuição acumulada de uma normal padrão, conhecida como padronização, ou a função de densidade de distribuição de probabilidade acumulada da normal

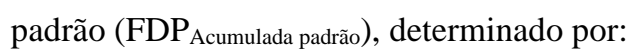

$\mathrm{P}(\mathrm{Z} \leq \mathrm{z})=\mathrm{F}(\mathrm{Z})=\frac{1}{\sqrt{2 \pi}} \int_{-\infty}^{\mathrm{z}} \mathrm{e}^{-\frac{\mathrm{Z}^{2}}{2}} \mathrm{dZ}$

Baseado na $\mathrm{FDP}_{\text {Acumulada padrão, foram determinados os parâmetros de eficiência para avaliação do sistema de irrigação }}$ localizada por meio da integração da $\mathbf{F}(\mathbf{Z})$. Onde os valores de probabilidade da $\operatorname{FDP}_{\text {Acumulada padrão, }} \operatorname{Prob}(Z \leq z)$, que representam as percentagens da fração da área que recebeu o volume de água $\left(X=F_{a c}\right)$, foram calculados integrando $F(Z)$ de infinito negativo a um valor de "z" qualquer, de acordo com a Equação 4. O MPNL que utiliza a FDP Acumulada padrão (Equação 10), ilustrado na Figura 1, é construído com os volumes de água coletados dos emissores ordenados em ordem decrescente, obtidos a partir dos ensaios realizados em campo para o cálculo da uniformidade de distribuição e eficiência de aplicação de água em função da fração da área total irrigada, representada por cada um dos volumes de água coletados dos emissores, dos quais o percentual de área que está sendo irrigada pode ser determinada de forma adequada e, também, a área que está sendo irrigada de maneira deficitária.

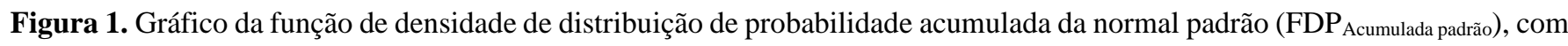
base no modelo proposto por Anyoji e Wu (1994) para avaliação de sistemas de irrigação localizada.

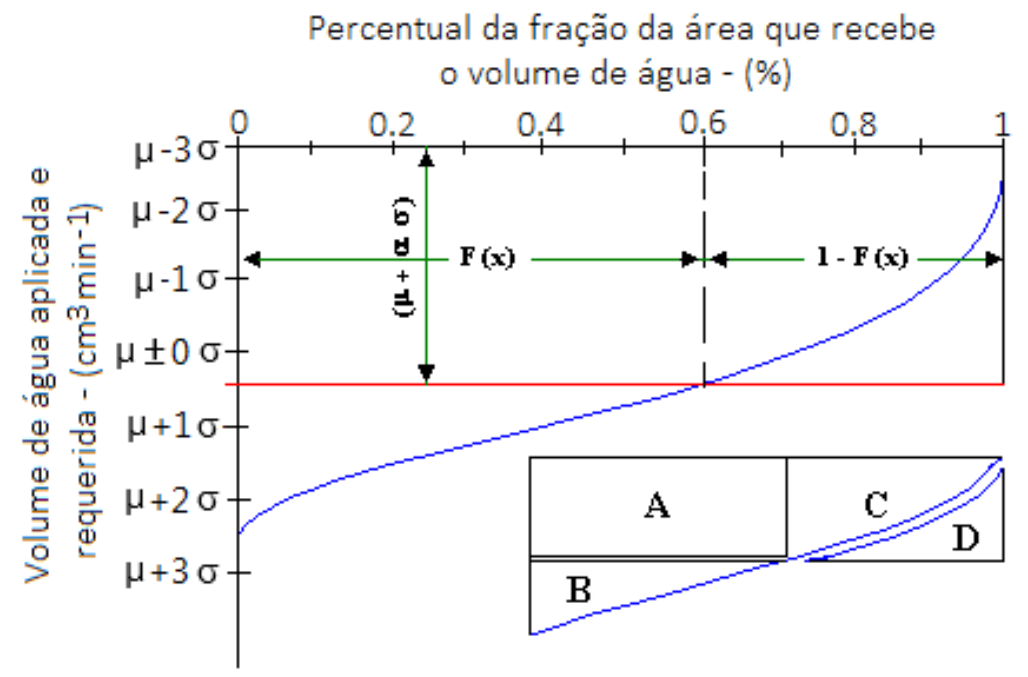

Fonte: Andrade et al. (2021). 


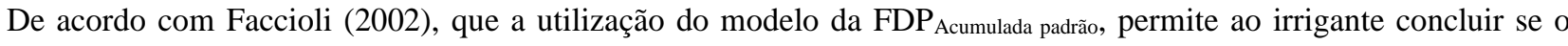
manejo adotado é correto ou não, uma vez que é possível identificar, por meio do gráfico da FDP Acumulada padrão (Figura 1), as várias frações da área irrigada que receberam o volume de água aplicado pelos emissores: a fração da área com déficit de água $\left(F_{a d}=\right.$ área $\left.D\right)$, fração da área possui una percolação profunda ou fração da área que recebeu excesso de água $\left(F_{p p}=\right.$ área $\left.B\right)$, fração da área armazenada que é disponibilizada às plantas ou área adequadamente irrigada $\left(\mathrm{F}_{\mathrm{ar}}=\right.$ área $\left.\mathrm{A}\right)$ e a fração da área com quantidade insuficiente de água, ou seja, que não suprir todas as demandas ou necessidades de água das plantas $\left(\mathrm{F}_{\mathrm{ai}}=\right.$ área $\mathrm{C}$ ).

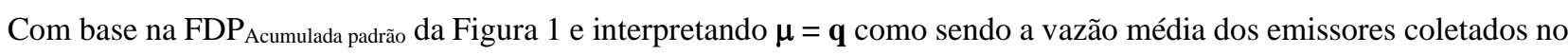
campo com desvio-padrão $(\sigma)$, verifica-se que, quando a função de distribuição de probabilidade acumulada é zero, indica que $0 \%$ da área está recebendo mais de q $+3 \sigma$, porém, quando igual a um, $100 \%$ da área está recebendo mais de q - $3 \sigma$, em que esses dois valores extremos q $\pm 3 \sigma$, são denominados limites de confiança que refletem o grau de segurança da amostragem e o risco ou incerteza, associados ao valor médio estimado. Se o volume de água requerida pelas culturas é especificado como sendo $\mathrm{q}+\alpha \sigma$, onde $\alpha$ é um valor constante, quatro áreas $\mathrm{A}, \mathrm{B}, \mathrm{C}$ e D são identificadas na FDP $\mathrm{Acumulada} \mathrm{padrão}_{\text {e representam a }}$ quantidade total de água aplicada sobre uma área base e suas proporções relativas (Figura 1).

Observa-se na Figura 1, a quantidade armazenada na zona radicular $(A+C)$, a percolação profunda (B) e a quantidade de déficit (D) onde a integração dessas áreas permite obter os parâmetros que determinam as eficiências do sistema de irrigação localizada baseado na vazão do emissor: Ea, Es, Ed, Epa, Pp, Gd e Gad. Os resultados das integrações das áreas definidas no



Água armazenada na zona radicular disponível à cultura, área (A+C) determinada pela Equação 5:

$\mathrm{A}+\mathrm{C}=\frac{\sigma}{\sqrt{2 \pi}} \mathrm{e}^{-\frac{\alpha^{2}}{2}}+\mu \cdot \mathrm{F}(\mathrm{Z})$

Volume de água disponível à cultura ou área adequadamente irrigada, área (A) determinada pela Equação 6:

$A=F(Z)(\mu+\alpha \sigma)$

Área que representa o excesso de água ou perda de água por percolação (B) substituindo-se Equação (6) em (5):

$\mathrm{B}=\frac{\sigma}{\sqrt{2 \pi}} \mathrm{e}^{-\frac{\alpha^{2}}{2}}-\alpha \mu \mathrm{F}(\mathrm{Z})$

Área que representa o volume de água aplicado deficitariamente (C), dada por:

$\mathrm{C}=\mu(1-\mathrm{F}(\mathrm{Z})) \sigma-\frac{\sigma}{\sqrt{2 \pi}} \mathrm{e}^{-\frac{\alpha^{2}}{2}}$

Área que representa o volume de déficit é obtida a partir da Figura 1, que mostra que a área $(\mathrm{C}+\mathrm{D})$ pode ser expressa simplesmente como:

$\mathrm{C}+\mathrm{D}=(1-\mathrm{F}(\mathrm{Z}))(\mu+\alpha \sigma)$ 
Então, substituindo-se a Equação (6) na (7) ter-se-á:

$\mathrm{D}=(1-\mathrm{F}(\mathrm{Z})) \alpha \sigma+\frac{\sigma}{\sqrt{2 \pi}} \mathrm{e}^{-\frac{\alpha^{2}}{2}}$

Utilizando-se as Equações (5) a (10) foram determinados os parâmetros que avaliam a eficiência do sistema de irrigação localizada, como segue:

- Eficiência de aplicação (Ea)

$$
\mathrm{E}_{\mathrm{a}}=\frac{\mathrm{A}+\mathrm{C}}{\mathrm{A}+\mathrm{B}+\mathrm{C}}
$$

- Eficiência de armazenamento (Es)

$$
\mathrm{E}_{\mathrm{S}}=\frac{\mathrm{A}+\mathrm{C}}{\mathrm{A}+\mathrm{C}+\mathrm{D}}
$$

- Percolação profunda (Pp)

$$
\mathrm{P}_{\mathrm{p}}=\frac{\mathrm{B}}{\mathrm{A}+\mathrm{C}+\mathrm{B}}
$$

- Percentagem de déficit $\left(\mathrm{G}_{\mathrm{d}}\right)$

$$
\mathrm{G}_{\mathrm{d}}=\frac{\mathrm{D}}{\mathrm{A}+\mathrm{C}+\mathrm{D}}
$$

- Grau de adequação da irrigação $\left(\mathrm{G}_{\mathrm{ad}}\right)$

$$
\mathrm{G}_{\mathrm{ad}}=\frac{\mathrm{C}}{\mathrm{A}+\mathrm{B}+\mathrm{C}}
$$

Modelo de regressão não linear (MRLN) baseado na função de distribuição cumulativa corresponde a função polinomial acumulada $\left(F P_{\text {Acumulada }}\right)$

O modelo de regressão não linear (MRLN) utilizado para avaliar relação entre a variável explicativa (variável independentes, preditora $\left(\mathrm{X}=\mathrm{F}_{\mathrm{ac}}\right)$ e uma única variável resposta (variável dependente, prevista) $\left(\mathrm{Y}=\mathrm{V}_{\mathrm{c}}\right)$ foi a regressão da equação polinomial (Karmeli, 1978; Martins, 2000). O MRLN proposto no estudo é baseado em uma FP Acumulada que expressa a relação entre os dados da variável $\mathrm{X}$, representada pela fração da área que recebeu quantidade de água dos emissores $\left(\mathrm{F}_{\mathrm{ac}}\right)$ e a variável $\mathrm{Y}$, que representa o volume de água coletada no campo $\left(\mathrm{V}_{\mathrm{c}}\right)$, por meio de alguma função matemática: linear, quadrática,

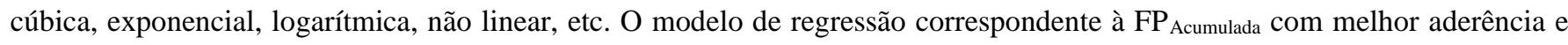
relação aos dados experimentais foi uma função polinomial do terceiro grau, representada pela seguinte expressão:

$$
\mathrm{Yi}(\mathrm{Xi})=\beta_{\mathrm{o}}+\beta_{1} \mathrm{Xi}+\beta_{2} \mathrm{Xi}^{2}+\beta_{3} \mathrm{Xi}^{3} \varepsilon \mathrm{i}
$$

Em que Yi é a variável dependente; Xi a variável independente; $\beta_{0}, \beta_{1}, \beta_{2}$, e $\beta_{3}$ são os coeficientes que fornecem o melhor ajuste aos dados amostrados à serem estimados, denominados de coeficientes do modelo; ci é o desvio, ou erro normal 
de média zero e variância $\sigma^{2}$; e "i” são os elementos da amostra, variando de 1 a n. Os valores da $\mathrm{FP}_{\text {Acumulada }}$ correspondente a função de polinômio do terceiro grau, $\operatorname{Prob}(X \leq x)=Y(X)$, que representa as percentagens da fração da área que recebeu $o$ volume de água $\left(X=F_{a c}\right)$. A Equação 22, que também poderíamos chamar de verdadeiro modelo de regressão, é exata no sentido de que se os coeficientes $\beta$ e o erro $\varepsilon$ forem conhecidos, permite reproduzir exatamente o valor observado Y. O que se busca neste modelo é a determinação da função de distribuição de probabilidade acumulada ( $\mathrm{FP}_{\text {Acumulada }}$ ) que melhor se ajusta aos valores de $\mathrm{V}_{\mathrm{c}}$ (dados observados), de acordo com a Equação 17:

$\mathrm{Y}(\mathrm{X})=\mathrm{P}(\mathrm{X} \leq \mathrm{x})=$ função acumulativa não linear

Onde $\mathrm{Y}(\mathrm{X})$ é a função de probabilidade acumulada do volume de água coletado para uma determinada fração de área "x" que recebeu quantidade de água dos emissores até um fração de área "X" qualquer. Que é obtida pela integral da Equação 17, variando de infinito negativo a " $x$ ", onde "x" é o valor da variável aleatória $F_{a c}$, resultando assim na probabilidade do valor obtido nessa integração ser menor ou igual à "x".

$\mathrm{P}(\mathrm{X} \leq \mathrm{x})=\mathrm{Y}(\mathrm{X})=\int_{-\infty}^{\mathrm{X}} \mathrm{Yi}(\mathrm{Xi}) \mathrm{dX}$

O procedimento estatístico para estimação dos coeficientes $\beta_{0}, \beta_{1}, \beta_{2}$, e $\beta_{3}$ da $\mathrm{FP}_{\text {Acumulada }}$ descrita pela Equação 18 , foi realizada pelo do método dos mínimos quadrados, que consiste na estimativa de valores que minimizam a soma dos quadrados dos desvios, a partir de dados fornecidos pela amostra. Para verificar se o modelo de regressão não linear (MRNL) por meio da equação polinomial do terceiro grau está adequado (modelo bem ajustado), foi realizada análise de significância dos parâmetros da regressão e utilizando o coeficiente de determinação $\left(R^{2}\right)$, que estabelece a parcela da variabilidade amostral realmente explicada pela equação de regressão. Esse coeficiente é determinado de acordo com a Equação 19:

$\mathrm{R}^{2}=\frac{\mathrm{SQ}_{\text {Regressão }}}{\mathrm{SQ}_{\text {Total }}}$

Onde $S Q_{\text {Regressão }}$ representa a soma de quadrado da regressão e $\mathrm{SQ}_{\text {Total }}$ a soma de quadrado total. $\mathrm{A} \mathrm{SQ}_{\text {Total }}$ é dada por:

$\mathrm{SQ}_{\text {Total }}=\mathrm{SQ}_{\text {Regressão }}+\mathrm{SQ}_{\text {Resíduo }}$

De acordo com Santos et al. (2015), a qualidade do ajuste na regressão está relacionada com coeficiente de determinação $\left(\mathrm{R}^{2}\right)$, quanto menor for a dispersão dos dados, melhor a regressão representa o conjunto de valores observados. Os parâmetros de ajuste do modelo de regressão proposto foram determinados por meio da rotina Solver da planilha Excel. O mesmo procedimento matemático de integração utilizado no modelo MPNL para determinar as frações acumulada das áreas irrigadas que delimitam as quatro áreas A, B, C e D (Figura 1), também foi aplicado no MRNL, na qual o ajuste da equação polinomial do terceiro grau representa a quantidade total de água aplicada em uma área base e suas proporções relativas em função dos valores de volume de água coletados pelos emissores $\left(\mathrm{V}_{\mathrm{c}}\right)$ obtidos dos testes realizados em campo, que permitiram calcular os parâmetros que determinam avaliar a eficiência de aplicação de água do sistema de irrigação localizada: Ea, Es, Ed, Epa, Pp, Gd e Gad). Também é admissível através do MRLN concluir se o manejo de irrigação está correto ou não, uma vez que é possível 
identificar, através do gráfico da equação polinomial, os percentuais ou frações da área irrigada que mais recebeu quantidade de água dos emissores.

\section{Validação dos pré-requisitos dos resíduos e análise da validação dos modelos}

\section{Validação dos pré-requisitos dos resíduos}

Antes de ajustar o MPNL e MRNL, a adequação dos modelos foi avaliada através da validade das hipóteses de normalidade dos resíduos, homogeneidade (as observações são identicamente distribuídas), aleatoriedade de erros (diferença residual entre valores observados e previstos a partir de $\mathrm{Y}$, deva ser independente para cada valor de $\mathrm{X}$, ou seja, não correlacionado) e detectar prováveis pontos influentes e valores atípicos (também denominados outliers):, respectivamente, aplicando o teste estatística de Shapiro-Wilk (SW), testes gráficos Q-Q plot e P-P plot, e gráfico de Scatterplot dos resíduos.

Para verificar a adequação do ajuste da distribuição dos valores do $\mathrm{V}_{\mathrm{a}}$ à distribuição teórica normal, foram utilizados dois testes aderência à normalidade, o primeiro analítico, por meio do resíduo que está presente em uma estatística amplamente utilizada para avaliar o ajuste do modelo, denominada teste estatística de Shapiro-Wilk (SW) ao nível de significância ( $\alpha$ ) de 1 e $5 \%$, capaz de comparar a distribuição observada com aquela determinada pelo modelo por meio da seguinte expressão (Schmidt, 2003):

$$
\mathrm{SW}=\frac{\left(\sum_{i=1}^{\mathrm{n}} \mathrm{a}_{\mathrm{i}} \mathrm{X}_{(\mathrm{i})}\right)^{2}}{\sum_{\mathrm{i}=1}^{\mathrm{n}}\left(\mathrm{x}_{\mathrm{i}}-\overline{\mathrm{X}}\right)^{2}}
$$

Onde SW é a função de variância estimada para a distribuição de probabilidade em estudo, os $\mathrm{X}_{(\mathrm{i})}$ são os valores amostrais ordenados e os $a_{i}$ são constantes geradas a partir das médias, variâncias e covariâncias das estatísticas de ordem de uma amostra aleatória de tamanho "n" proveniente de uma distribuição normal, e i é o número de ordem das quantidades de água medidas e calculadas.

Para verificar tanto a hipótese de normalidade como também ajuste ou adequabilidade dos modelos propostos, foi utilizado o teste não analítico, por meio dos gráficos Q-Q plot (Quantil-Quantil) e P-P plot (Percentil-Percentil). O procedimento utilizado do Q-Q plot, consiste em comparar a distribuição amostral ou empírica (distribuição dos dados observados) com uma distribuição teórica (distribuição dos valores estimados pelos modelos) que, neste caso, são os modelos MPNL e MRNL. Neste gráfico, os pares ordenados são representados pelos quantis da amostra (valores dos quantis observados referente ao volume de água coletado $-V_{c}$ ) e seus respectivos quantis na distribuições dos modelos MPNL e MRNL (valores dos quantis estimados pelos modelos $-\mathrm{V}_{\mathrm{c}}$ ).

O P-P Plot é um gráfico dos percentis de distribuição teórica contra os percentis da outra distribuição amostral. No caso deste gráfico, o ajuste dos dados pode ser comparado em termos da probabilidade acumulada, comparando a função de distribuição acumulada da amostra e a função de distribuição acumulada ajustada pelos modelos MPNL e MRNL (Hartmann et al., 2011). A ideia da avaliação deste gráfico é a mesma dos quantis: se a distribuição amostral (dados observados) for semelhante à distribuição teórica (dados estimados), os pontos no gráfico terão uma tendência linear. No entanto, os dois gráficos não informam se a distribuição está próxima suficiente da normalidade e se os dados observados estão bem ajustados pelos modelos, uma vez que dependem de interpretação visual (Barros et al., 2012). 
Para os dois testes gráficos, a forma como os pontos se desviam do comportamento linear pode fornecer pistas sobre a natureza da não normalidade, bem como a falta de ajuste dos modelos MPNL e MRNL. Se existir uma boa aderência dos dados à distribuição normal, no diagrama Q-Q plot, os pontos são apresentados alinhados a equação da linear que representa a identidade dos quantis amostrais e teóricos da distribuição normal, e com valor de $\mathrm{R}^{2}$ acima de 0,80 . Segundo (Harrell, 2015), o $\mathrm{R}^{2}$ é um indicador para a análise do ajuste do modelo adotado, indicando a proporção da variabilidade de $\mathrm{Y}\left(\mathrm{V}_{\mathrm{c}}\right)$ que pode ser explicada pela variabilidade das variáveis $\mathrm{X}\left(\mathrm{F}_{\mathrm{ac}}\right)$.

\section{Critérios de comparação dos modelos (modelo padrão MMP com o modelos propostos MPNL e MRNL)}

Os dois modelos probabilísticos propostos MPNL e MRNL foram comparados com o método-padrão (MMP), onde neste estudo o método matemático de Merrian \& Keller (1978) foi admitido como modelo padrão as análises realizadas. A precisão das estimativas de erros dos três modelos, que está relacionada com o afastamento dos valores dos parâmetros de eficiência de aplicação de águas pelo sistema de irrigação (Ea, Es, Ed, Epa, Pp, Gd e Gad) obtidos pelos dois modelos não lineares propostos em comparação aos valores de eficiência obtidos com MMP, foram avaliados através do desvio simples absoluto (DSA) dado por:

DSA $=\left|\mathrm{X}_{\text {modelos não lineares }}-\mathrm{X}_{\text {modelo matemático padrão }}\right|$

Onde DSA é o desvio simples absoluto entre os valores dos parâmetros de eficiência estimados pelos modelos não lineares (MPNL e MRNL) associadas a cada fração acumulativa da área irrigada e os valores calculados pelo método matemático padrão (MMP). O modelo ideal é aquele que apresenta, por um lado, os valores dos parâmetros de eficiências quanto mais próximo do valor obtido com o MMP, ou seja, o melhor modelo é o que possui menor valor de DSA.

Além disso, fez-se a plotagem gráfica das relações entre os valores observados e estimados pelos modelos MPNL e MRN, com a finalidade selecionar o melhor dentre estes modelos. Foi realizada à análise de regressão linear simples com a reta 1:1 ou de $45^{\circ}$ de inclinação passando pela origem entre $(0,0)$ e $(1,1)$ ajustado aos pares dos valores observados e estimados pelos modelos MPNL e MRNL de acordo com as recomendações de Monteiro et al. (2001). A partir deste ajuste, os modelos foram avaliados pelos coeficientes de determinação $\left(\mathrm{R}^{2}\right)$ e de correlação (r), pelo índice de concordância proposto por Willmott et al. (1985), conforme a Equação 23 e pelo índice de confiança de desempenho "C" (Equação 24) que é obtido pela multiplicação do coeficiente de correlação (r) pelo índice "d" de Willmott (Camargo \& Sentelhas, 1997; Conceição \& Coelho, 2003).

Os índices "d" e "c" tem variação entre 0 e 1, indicam o grau de exatidão, de desempenho e concordância entre valores estimados e observados, sendo que, quanto mais próximo de 1, melhor o grau de exatidão e desempenho do modelo, ao passo que o coeficiente de determinação $\left(\mathrm{R}^{2}\right)$ indica a precisão do modelo, ou seja, indica o quanto da variável dependente é explicada pelas variáveis independentes, e quanto mais próximos de 1, melhor o ajuste do modelo, isso indica o quanto os valores obtidos na previsão do modelo são similares aos resultados reais ou obtidos por meio de um método considerado como padrão (Bussab \& Morettin, 2010).

$$
\mathrm{d}=\frac{\sum_{\mathrm{i}=1}^{\mathrm{n}}\left(\mathrm{E}_{\mathrm{i}}-\mathrm{P}_{\mathrm{i}}\right)^{2}}{\sum_{\mathrm{i}=1}^{\mathrm{n}}\left(\left|\mathrm{E}_{\mathrm{i}}-\overline{\mathrm{O}}\right|+|\mathrm{O}-\overline{\mathrm{O}}|\right)^{2}}
$$


Onde $\mathrm{E}_{\mathrm{i}}=$ valor estimado; $\mathrm{O}_{\mathrm{i}}=$ valor observado e $\overline{\mathrm{O}}=$ média dos valores observados, $\mathrm{n}=$ representa o número de observações da amostra, e i é o número de ordem das quantidades de água medidas e calculadas.

O índice de confiança de desempenho (C) foi avaliado segundo escala proposta por Camargo \& Sentelhas (1997): Ótimo (c $>0,85)$; Muito Bom $(0,76 \leq \mathrm{c} \leq 0,85)$; Bom $(0,66 \leq \mathrm{c} \leq 0,75)$; Mediano $(0,61 \leq \mathrm{c} \leq 0,65)$; Sofrível $(0,51 \leq \mathrm{c} \leq 0,60)$; Mau $(0,41 \leq \mathrm{c} \leq 0,50)$, e Péssimo $(\mathrm{c} \leq 0,40)$.

Os parâmetros de desempenho dos dois modelos estatísticos não lineares com o método matemático padrão foram determinados por meio do programa Excel. Um outro meio para seleção dos modelos foi a soma dos quadrados dos resíduos (SQR). Segundo este critério, o melhor modelo é o que possui menor valor de SQR (Silva et al., 2011). Também foram utilizados quatro avaliadores da qualidade de ajuste que são frequentemente utilizados para selecionar modelos em várias áreas: Soma do quadrado dos resíduos (SQR), critério de informação de Akaike (AIC) e critério de informação bayesiano (BIC), proposto por Akaike (1974). De acordo com esses critérios, o melhor modelo será aquele que apresentar o menor valor de AIC ou BIC e SQR. O AIC não é um teste sobre o modelo, no sentido de testar hipóteses e não é um teste de hipóteses, e nem tem significância e nem p-valor (Burnham \& Anderson, 2002). O valor do AIC para um determinado conjunto de dados não tem qualquer significado. O AIC é útil ao comparar vários modelos. O modelo com o menor AIC é o "melhor" modelo, entre os modelos comparados.

\section{Resultados e Discussão}

\section{Determinação da uniformidade de emissão do sistema de irrigação por gotejamento}

Para realizar a estatística dos dados, as variação da vazão dos emissores ao longo das linhas laterais, o volume de água coletados pelos emissores $\left(\mathrm{V}_{\mathrm{c}}\right)$ obtidos dos testes realizados em campo, em unidades de vazão $(\mathrm{mL})$, foi transformada para valores de volume de aplicação de água pelos emissores $\left(\mathrm{V}_{\mathrm{a}}\right)$, em unidade de $\mathrm{cm}^{3} \mathrm{~min}^{-1} \mathrm{ou} \mathrm{Lh}^{-1}$ que normalmente é usada para irrigação localizada (Tabela 1). As vazões totais de água por ponto de emissão coletadas pelos emissores durante 5 minutos nos testes realizados em campo, com dois emissores por planta, com uma vazão de cada emissor (q) de $40 \mathrm{~cm}^{3} \mathrm{~min}^{-1}\left(2,40 \mathrm{Lh}^{-1}\right) \mathrm{são}$ apresentados na Tabela 1 . 
Tabela 1. Volumes totais de água coletados pelos emissores $\left(\mathrm{V}_{\mathrm{c}}\right)$ no tempo de 5 minutos, e dos volumes de aplicação de água pelos emissores $\left(\mathrm{V}_{\mathrm{a}}\right)$ obtidos nos testes de campo para avaliação do sistema de irrigação por gotejamento no cultivo de maracujá.

\begin{tabular}{|c|c|c|c|c|c|}
\hline \multirow[t]{2}{*}{ Lateral } & \multirow[t]{2}{*}{ Pontos de emissão } & \multicolumn{2}{|c|}{$\begin{array}{c}\text { Volume de água coletado em cada } \\
\text { emissor }(\mathrm{mL})\end{array}$} & \multicolumn{2}{|c|}{$\begin{array}{c}\text { Volume de aplicação de água pelos } \\
\text { emissores (Va) }\end{array}$} \\
\hline & & Emissor 1 & Emissor 2 & $\left(\mathrm{~cm}^{3} \mathrm{~min}^{-1}\right)$ & $\left(\mathbf{L h}^{-1}\right)$ \\
\hline \multirow{4}{*}{ Início 1/1 } & Primeiro $1 / 1$ & 176 & 171 & 69,40 & 4,16 \\
\hline & Segundo $1 / 3$ & 209 & 152 & 72,20 & 4,33 \\
\hline & Terceiro $2 / 3$ & 198 & 211 & 81,80 & 4,90 \\
\hline & Último $3 / 3$ & 166 & 155 & 64,20 & 3,85 \\
\hline \multirow{4}{*}{ Segunda 1/3 } & Primeiro $1 / 1$ & 210 & 242 & 90,40 & 5,42 \\
\hline & Segundo $1 / 3$ & 223 & 226 & 89,80 & 5,38 \\
\hline & Terceiro $2 / 3$ & 221 & 209 & 86,00 & 5,16 \\
\hline & Último $3 / 3$ & 204 & 190 & 76,80 & 4,72 \\
\hline \multirow{4}{*}{ Terceiro 2/3 } & Primeiro $1 / 1$ & 209 & 219 & 85,80 & 5,13 \\
\hline & Segundo $1 / 3$ & 199 & 244 & 88,60 & 5,31 \\
\hline & Terceiro $2 / 3$ & 150 & 217 & 73,40 & 4,40 \\
\hline & Último $3 / 3$ & 221 & 216 & 87,40 & 5,24 \\
\hline \multirow{4}{*}{ Final $3 / 3$} & Primeiro $1 / 1$ & 241 & 244 & 97,00 & 5,82 \\
\hline & Segundo $1 / 3$ & 248 & 238 & 97,20 & 5,83 \\
\hline & Terceiro $2 / 3$ & 247 & 255 & 100,40 & 6,02 \\
\hline & Último $3 / 3$ & 205 & 190 & 79,00 & 4,74 \\
\hline
\end{tabular}

Fonte: Andrade et al. (2021).

As vazões máxima (Qmáx), mínima (Qmín) e média (Qméd) observadas para o sistema foram respectivamente 100,40; 64,20 e 83,83 $\mathrm{cm}^{-3} \min$ (Tabela 2), estando a Qméd observada abaixo do valor citado pelo fabricante de $80 \mathrm{~cm}^{3} \mathrm{~min}^{-1}\left(40 \mathrm{~cm}^{-3}\right.$ min $\mathrm{x} 2$ emissores por planta). Esses resultados podem ser justificados em razão da baixa pressão de serviço utilizada no momento do teste, pelo entupimento dos emissores, pela topografia do terreno e pelas características hidráulicas do sistema (Júnior et al., 2016).

Com base nos valores da Tabela 1, foram calculados os parâmetros de uniformidade Coeficiente de uniformidade de distribuição de água de Christiansen (CUC) pelos emissores, uniformidade de distribuição de água (CUD), coeficiente estatístico de variação de vazão dos emissores $(\mathrm{CVq})$ e o coeficiente de uniformidade estatística (CUE) com a finalidade de avaliar a performance do sistema de irrigação por gotejamento, cujos valores foram 89,86\%, 90,37\%, 12,47\% e 99,88 \%, respectivamente (Tabela 2).

Tabela 2. Valores das vazões máxima (Qmáx), mínima (Qmín) e média (Qméd), coeficiente de uniformidade de distribuição de Christiansen (CUC), coeficiente de uniformidade de distribuição de água (CUD), coeficiente de variação de variação de vazão dos emissores $(\mathrm{CVq})$ e o coeficiente de uniformidade estatística (CUE) do sistema de irrigação por gotejamento no cultivo de maracujá. Fonte: Andrade et al. (2021).

\begin{tabular}{|c|c|c|c|c|c|c|}
\hline Qmáx & Qmín & Qméd & CUC & CUD & $\mathrm{CVq}$ & CUE \\
\hline -------------- & $-\mathrm{cm}^{3} \mathrm{~m}$ & - & 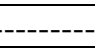 &  & 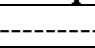 & - \\
\hline 100,40 & 64,20 & 83,83 & 89,86 & 90,37 & 12,47 & 99,88 \\
\hline
\end{tabular}

Fonte: Andrade et al. (2021).

De acordo com os critérios de classificação de desempenho hidráulico dos emissores, os valores de CUC, CUD e CUE indicam que o sistema é adequado, estando na categoria aceitável para sistemas de irrigação localizada, com exceção do CVq. Segundo Pizarro (1996) a CUD é um indicador de problemas distribuição da irrigação. A alta uniformidade é importante para irrigação em solos arenosos, onde a redistribuição lateral da água é limitada. 
Segundo Martín-Benito (1993) a uniformidade de distribuição de água nas novas instalações é próximo de 90\%, podendo diminuir consideravelmente com o uso contínuo. Portando, um valor de CUD de $80 \%$ é mais realista, pois os valores de eficiência podem ser menores devido a problemas de manejo. Para o autor, ao realizar um projeto de irrigação localizada, fatores econômicos contribuirão para determinar a seleção do CUD, devendo-se comparar o custo (e possibilidade) do maior consumo de água com o maior investimento inicial da instalação.

De acordo com Wu (1995) para valores de CUE maiores que 70\% e CVq próximo de 0,3, a hipótese de normalidade é aceita, ou seja, é possível ajustar uma distribuição normal aos dados de volume de aplicação de água dos emissores e, com isso, confirma-se que aplicação do método estatístico na avaliação das eficiências é válida. O CVq obtido de 12,47\% é classificado como pobre de acordo com Salomon (1979). O autor cita que valor < 3\% é considerado excelente; 3-7\% médio; 10-14\% pobre e > 14\% inaceitável. O CUE encontrado no presente estudo de 98,88\% está dentro do recomendado pela a norma da ASAE (1996) de 85\% a 90\%, em cultivos anuais em zonas áridas e topografia uniforme (Cuenca, 1998; Silva et al., 2017).

Avaliação da eficiência do sistema de irrigação por gotejamento aplicando o modelo matemático padrão ou tradicional MMP

Utilizando os dados da Tabela 1 e com base no valor do volume de água requerida pela cultura ou volume de irrigação real necessário para a cultura de $175 \mathrm{~cm}^{3} \cdot$ planta $^{-1} \cdot \mathrm{min}^{-1}$, calculou-se o volume de aplicação $\left(\mathrm{V}_{\mathrm{a}}\right)$, o volume de armazenamento $\left(V_{s}\right)$, o volume percolado $\left(V_{p}\right)$ e o volume de déficit $\left(V_{d}\right)$ em litros por planta dia, onde os valores encontrados são apresentados na Tabela 3 .

Tabela 3. Volumes de água apliacada $\left(V_{a}\right)$, armazenada $\left(V_{s}\right)$, percolada $\left(V_{p}\right)$ e de déficit $\left(V_{d}\right)\left(\mathrm{cm}^{3} \cdot\right.$ planta ${ }^{-1}$ min $\left.^{-1}\right)$ para o tempo de coleta de 5 minutos no sistema de irrigação por gotejamento no cultivo de maracujá.

\begin{tabular}{|c|c|c|c|c|c|}
\hline \multirow[b]{2}{*}{ Lateral } & \multirow[b]{2}{*}{ Ponto de emissão } & \multicolumn{4}{|c|}{ Volume de água } \\
\hline & & $\begin{array}{c}\text { Aplicado } \mathrm{V}_{\mathrm{a}} \\
\left(\mathrm{cm}^{3} \cdot \text { planta }^{-1} \mathrm{~min}^{-1}\right)\end{array}$ & $\begin{array}{c}\text { Armazenado } V_{s} \\
\left(\mathrm{~cm}^{3} \cdot \mathrm{min}^{-1}\right)\end{array}$ & $\begin{array}{c}\text { Percolado } V_{p} \\
\left(\mathrm{~cm}^{3} \cdot \mathrm{min}^{-1}\right)\end{array}$ & $\begin{array}{l}\text { Déficit V } V_{d} \\
\left(\mathrm{~cm}^{3} \cdot \mathrm{min}^{-1}\right)\end{array}$ \\
\hline \multirow{4}{*}{ Início 1/1 } & Primeiro $1 / 1$ & 347,00 & 347,00 & 0,00 & 3,00 \\
\hline & Segundo $1 / 3$ & 452,00 & 350,00 & 102,00 & 0,00 \\
\hline & Terceiro $2 / 3$ & 428,00 & 350,00 & 78,00 & 0,00 \\
\hline & Último $3 / 3$ & 485,00 & 350,00 & 135,00 & 0,00 \\
\hline \multirow{4}{*}{ Segunda 1/3 } & Primeiro $1 / 1$ & 361,00 & 350,00 & 11,00 & 0,00 \\
\hline & Segundo $1 / 3$ & 449,00 & 350,00 & 99,00 & 0,00 \\
\hline & Terceiro $2 / 3$ & 443,00 & 350,00 & 93,00 & 0,00 \\
\hline & Último $3 / 3$ & 486,00 & 350,00 & 136,00 & 0,00 \\
\hline \multirow{4}{*}{ Terceiro 2/3 } & Primeiro $1 / 1$ & 409,00 & 350,00 & 59,00 & 0,00 \\
\hline & Segundo $1 / 3$ & 430,00 & 350,00 & 80,00 & 0,00 \\
\hline & Terceiro $2 / 3$ & 367,00 & 350,00 & 17,00 & 0,00 \\
\hline & Último $3 / 3$ & 502,00 & 350,00 & 152,00 & 0,00 \\
\hline \multirow{4}{*}{ Final 3/3 } & Primeiro $1 / 1$ & 321,00 & 321,00 & 0,00 & 29,00 \\
\hline & Segundo $1 / 3$ & 394,00 & 350,00 & 44,00 & 0,00 \\
\hline & Terceiro $2 / 3$ & 437,00 & 350,00 & 87,00 & 0,00 \\
\hline & Último $3 / 3$ & 395,00 & 350,00 & 45,00 & 0,00 \\
\hline \multicolumn{2}{|c|}{ Total } & 6706,00 & 5568,00 & 1138,00 & 32,00 \\
\hline
\end{tabular}

Fonte: Andrade et al. (2021).

A partir dos dados da Tabela 3, foram calculados os parâmetros de eficiência referentes à avaliação do sistema de irrigação por gotejamento utilizando critérios matemáticos padrão ou tradicional (MMP). Os valores de Ea, Es, Pp e Gd observados para sistema foram, respectivamente, $83,03 \%, 99,43 \%, 16,97 \%$ e $0,57 \%$, conforme descrito na Tabela 4 . 
Tabela 4. Parâmetros de avaliação de eficiência do sistema de irrigação por gotejamento em cultivo de maracujá, por meio do Método matemático tradicional (MMP).

\begin{tabular}{cccc}
\hline \multicolumn{4}{c}{ Parâmetros de eficiência do sistema de irrigação pelo método matemático tradicional (MMP) } \\
\hline Ea & Es & Pp & Gd \\
\hline$-13,03$ & 99,43 & 16,97 & 0,57 \\
\hline
\end{tabular}

Ea = Eficiência de aplicação; Es = Eficiência de armazenamento (Es); Pp = Percolação profunda; Gd = Percentagem de déficit e Gag = Grau de adequação da irrigação. Fonte: Andrade et al. (2021).

Considerando a eficiência de aplicação, observa-se que, de toda a água aplicada, 83,03\% permanece útil às plantas, sendo que 16,97\% constituindo perdas por percolação profunda. A eficiência de armazenamento indica que o reabastecimento da zona radicular foi de 99,43\%, com um déficit de apenas 0,57\%. Também se pode notar que a Es foi alta, indicando que ocorreu excesso de irrigação, resultando em considerável perda por percolação. Em geral, os resultados encontrados para os parâmetros de eficiência de aplicação de água estão dentro dos padrões de classificação de desempenho dos emissores, ou seja, são adequados para um sistema de irrigação por gotejamento, de acordo com ASAE (1996). Segundo a ASAE (American Society of Agricultural Engineers), a eficiência ótima dos sistemas de irrigação localizada por gotejamento varia entre 80 a $90 \%$.

\section{Avaliação da eficiência de aplicação de água do sistema de irrigação por gotejamento através do modelo probabilístico não linear proposto por Anyoji e Wu (1994) - MPNL}

Dentre as possibilidades de utilização de funções contínuas para avaliar o desempenho de sistemas de irrigação, destacase a função densidade de probabilidade acumulada normal ou função da distribuição acumulada normal padrão, que, por sua natureza matemática, pode, em princípio, favorecer a derivação de expressões matemáticas explícitas para o cálculo dos indicadores de uniformidade e de eficiência da irrigação, a partir do ajuste das lâminas ou do volume de aplicação de água pelos emissores em função da fração da área irrigada acumulada para cada observação. Um das principais premissas para aplicação da distribuição acumulada normal na avaliação da eficiência de aplicação de água, segundo Levine et al. (2000) é a hipótese de normalidade dos dados observados. Essa hipótese requer que os valores de lâminas ou volume de aplicação de água pelos emissores (Yi) sejam normalmente distribuídos para cada valor da fração da área irrigada (Xi).

Para verificar o pré-requisito da normalidade e da adequação do ajuste da distribuição dos valores do $\mathrm{V}_{\mathrm{a}}$ (dados observados) e dos valores simulados pela distribuição teórica normal, foram aplicados os testes Shapiro-Wilk (SW) e os testes gráficos do diagrama Q-Q plot normal e P-P plot dos dados. O valor $\mathrm{SW}_{\text {(calculado) }}=0,9313$ foi maior que $\mathrm{SW}_{\text {(tabelado) }}=0,904$ (pvalor > 0,01) com grau de probabilidade (GL) de 32 e a nível de significância de $1 \%$, resultando na aderência aos parâmetros de normalidade, e que a hipótese de normalidade é aceita, e a distribuição normal pode ser ajustada aos valores do volume de aplicação de água dos emissores. Esses resultados foram semelhantes aos obtidos por Anyoji e Wu (1994), avaliando a distribuição normal de probabilidades em um sistema de irrigação por gotejamento, verificaram que essa representa adequadamente a lâmina de água aplicada por gotejadores. Este fato reforça que a distribuição normal de probabilidade pode ser usada para descrever a lâmina de água aplicada por diferentes aspersores, bem como de diferentes sistemas de irrigação. Walker (1979) citado por Faccioli (2002) utilizou o teste qui-quadrado, com 95\% de nível de confiança, para comparar o ajuste normal aos valores de precipitação dos aspersores. Esses autores encontraram que o ajuste normal foi adequado para todos os valores lâmina de água aplicada pelos aspersores.

Verifica-se pelo diagrama Q-Q plot que existem poucos pontos dispersos e bem alinhados em torno da equação linear (os pontos seguem um padrão linear), com um valor alto do coeficiente de determinação ( $\left.\mathrm{R}^{2}\right)$ de 0,952 ao nível de significância 
de $1 \%$, evidenciando a normalidade dos dados observados, e conclui-se que a MPNL por meio do ajuste da FDP Acumulada padrão serve como um modelo plausível para explicar e descrever a distribuição dos dados observados $\left(\mathrm{V}_{\mathrm{a}}\right)($ Figura 2).

Figura 2. Diagrama Q-Q plot para avaliar a adequação do modelo e da normalidade dos resíduos dos valores do volume de água aplicado pelos emissores $\left(\mathrm{V}_{\mathrm{a}}\right)$ pelo sistema de irrigação por gotejamento em cultivo de maracujá por meio do modelo estatístico probabilístico não linear (MPNL) proposto por Anyoji e Wu (1994).

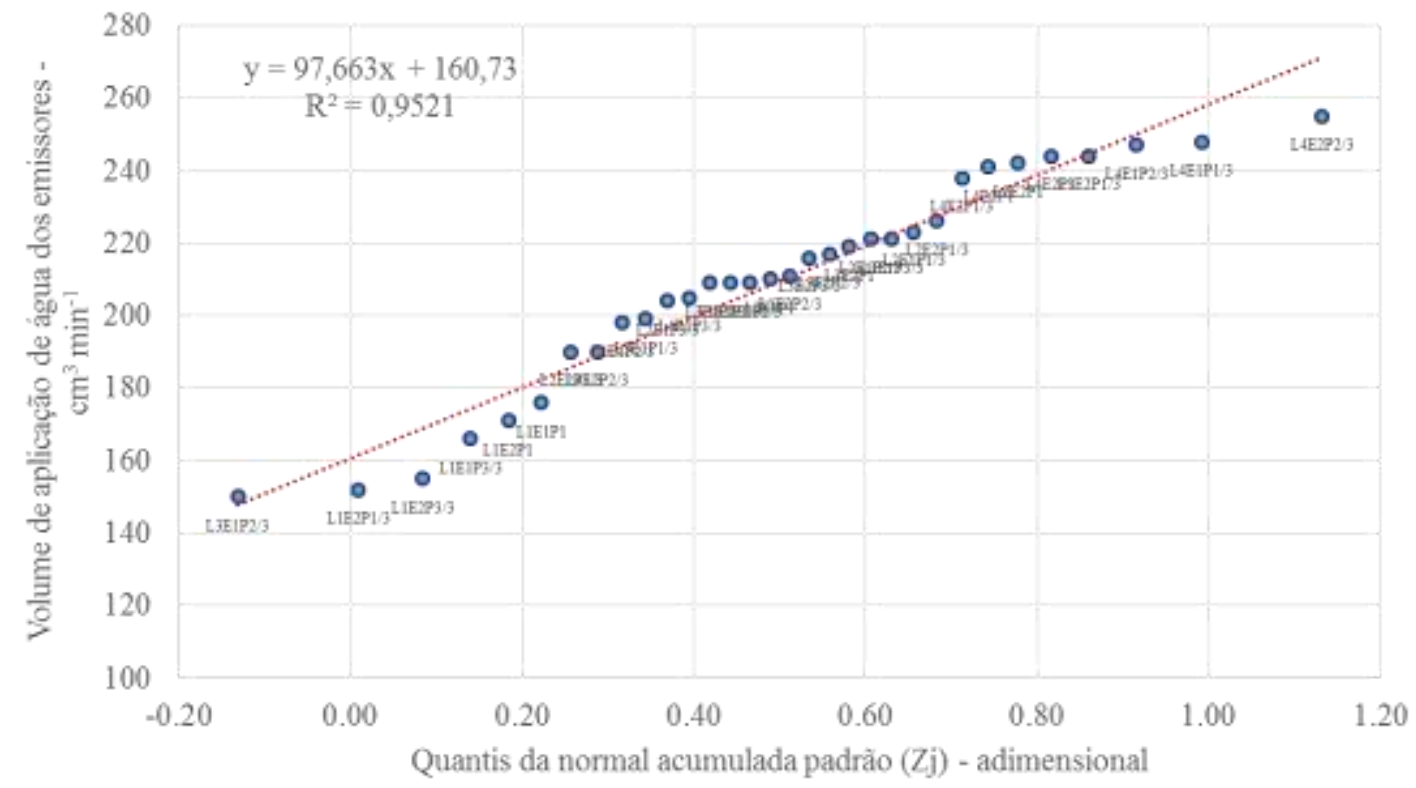

Notação: LEP - L = representa as linhas de gotejo ao longo da derivação do sistema de irrigação (4 linhas: L1, L2 e L3); E = número de emissores por planta (2 emissores: E1 e E2) e P = Posição dos emissores na linha de gotejo (4 posições: P1, P1/2 e P3/3). Fonte: Andrade et al. (2021).

Conforme descrito em Nóbrega (2010) os efeitos dos pontos marcados fora da reta, por não seguirem a mesma configuração dos demais pontos, são julgados como pontos de emissão significativos em termos de diferença entre valores de $\mathrm{V}_{\mathrm{a}}$ de cada ponto de coleta, ou seja, diferem entre si estatisticamente (Figura 2). Os pontos com efeitos ou diferenças significantes positivos são marcados acima da reta, ao passo que aqueles negativos são marcados abaixo desta. Como se pode ver pelo referido gráfico Q-Q plot, a clara existência de diferença significativa entre os valores de volume de água aplicado pelos emissores ( $\mathrm{V}_{\mathrm{a}}$ ) nos seguintes pontos de emissão (pontos de coleta): L1E2P1/3, L1E2P3/3, L4E1P1/3 e L4E2P2/3, ou seja, pontos esses que apresentaram diferença nos valores de $\mathrm{V}_{\mathrm{a}}$ em comparação com os demais.

Ainda pelo gráfico Q-Q plot (Figura 2), observa-se espaços ou lacunas abertas em torno da origem e ao final da curva dos valores de quantis, denominados "gaps", indicando a presença de valores discrepantes nos dados. Esses valores discrepantes influenciam na uniformidade de distribuição e na eficiência de aplicação da água reduzir os valores dos parâmetros de eficiência do sistema de irrigação. Segundo Hund et al., (2002) para a identificação de valores discrepantes no gráfico de probabilidade QQ plot é mais perceptível a visualização de abertura (gaps) em torno das caudas da distribuição, na origem e no final dos dados.

A estatística do diagrama P-P plot da Figura 3, corrobora a afirmação anterior (teste testes Shapiro-Wilk e Q-Q plot) mostrando normalidade dos dados observados, em que a distribuição acumulada dos percentis dos volumes de água aplicados pelos emissores é comparada com os valores acumulados dos percentis dos dados obtidos pela distribuição teórica. No diagrama P-P plot, os pontos plotados devem recair em uma reta de $45^{\circ}$ de inclinação entre $(0,0)$ e $(1,1)$.

Pela Figura 3, é possível identificar visivelmente que um pequeno número de pontos está acima e próximo da reta de $45^{\circ}$ de inclinação (diagonal) sem desvios fortes e pouquíssimos pontos abaixo, mostrando uma leve assimetria à direita da 
distribuição, e não compromete a aceitação (confirmação) da hipótese de normalidade dos dados observados. Isso indica que os resíduos estão aparentemente distribuídos normalmente, e confirmar o resultado do teste de normalidade de Shapiro-Wilk.

Figura 3. Diagrama P-P plot para avaliação da adequação do modelo e da normalidade dos resíduos dos valores do volume de água aplicado pelos emissores $\left(\mathrm{V}_{\mathrm{a}}\right)$ do sistema de irrigação por gotejamento na cultura de maracujá por meio do modelo probabilístico não linear (MPNL). Fonte: Andrade et al. (2021).

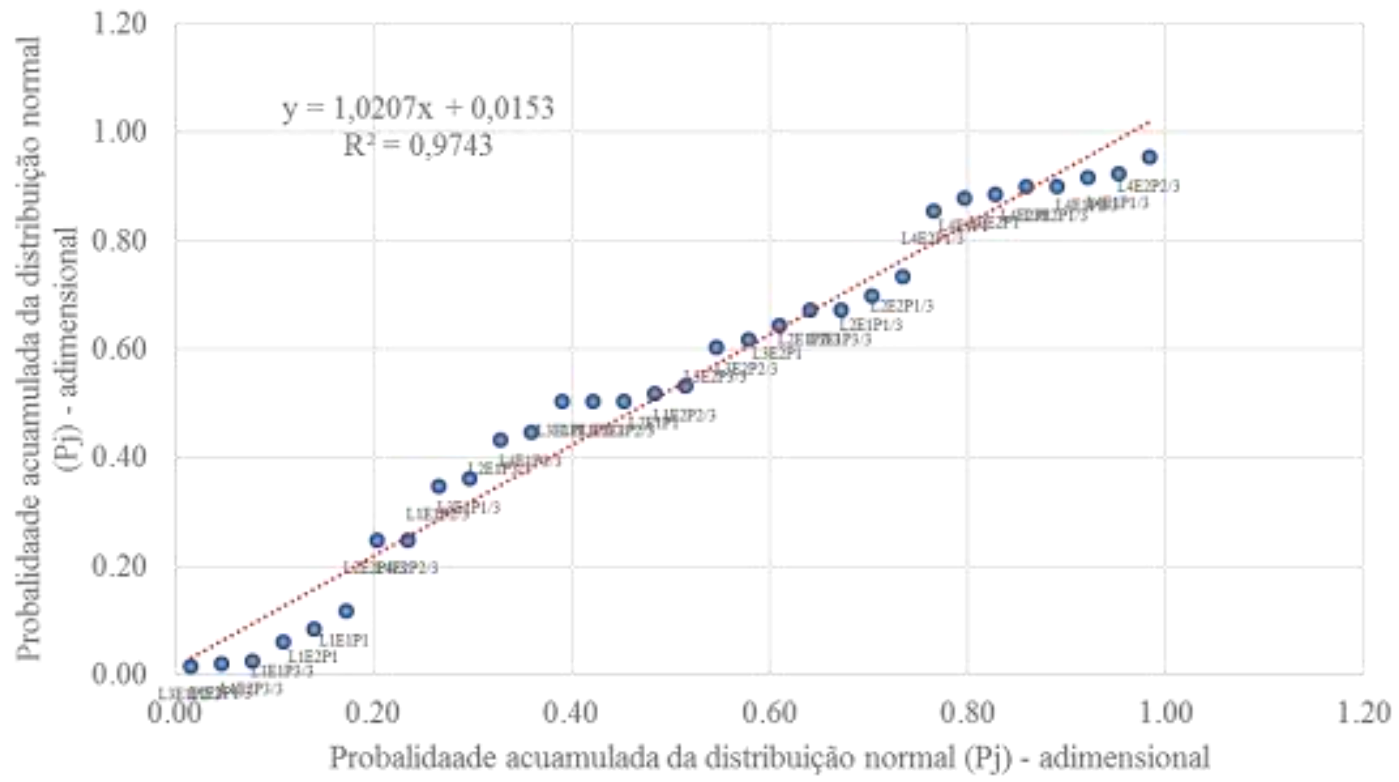

Notação: LEP - L = representa as linhas de gotejo ao longo da derivação do sistema de irrigação (4 linhas: L1, L2 e L3); E = número de emissores por planta (2 emissores: E1 e E2) e P = Posição dos emissores na linha de gotejo (4 posições: P1, P1/2 e P3/3). Fonte: Andrade et al. (2021).

De acordo com o gráfico de probabilidade P-P mostrado na Figura 3, não é evidenciada qualquer diferença significativa nos dados sendo que os gaps observados no gráfico, embora consideravelmente pequenos, indicam a presença de valores discrepantes nos dados.

Com base nos resultados e discussões anteriores, da confirmação da aceitação da normalidade dos dados observados, o gráfico do modelo da distribuição normal acumulada padrão dos valores de volume de água aplicado pelos emissores $\left(\mathrm{V}_{\mathrm{a}}\right)$ foi construído em função do percentual ou fração da área irrigada acumulada $\left(\mathrm{F}_{\mathrm{ac}}\right)$ que recebeu esse volume de água (Figura 4). Neste caso, é possível observar que os valores observados do $\mathrm{V}_{\mathrm{a}} \mathrm{e}$ os valores estimados pelo ajuste dos dados à distribuição acumulada normal padrão estão próximos, indicando boa adequação, o que implica que o MPNL é confiável, sendo portanto, adequado a assumir que o modelo explica uma parte significativa da variação da estatura em função da variabilidade do $\mathrm{V}_{\mathrm{a}}$. A linha cheia de cor vermelha corresponde aos valores observados da $\mathrm{V}_{\mathrm{a}} \mathrm{e}$ a linha pontilhada em preto aos valores estimados da $\mathrm{V}_{\mathrm{a}}$. Os números apresentados nos eixos das ordenadas $(\mathrm{x})$ a $\mathrm{F}_{\mathrm{ac}}$ correspondem aos números atribuídos a cada ponta de emissão dos emissores ou gotejadores no campo. 
Figura 4. Curva de ajuste da distribuição de probabilidade normal padrão dos volumes de água aplicados pelos emissores, $\mathrm{V}_{\mathrm{a}}$ (dados observados) em função da fração acumulada da área irrigada $\left(\mathrm{F}_{\mathrm{ac}}\right)$ do sistema de irrigação por gotejamento em cultivo de maracujá. Fonte: Andrade et al. (2021).

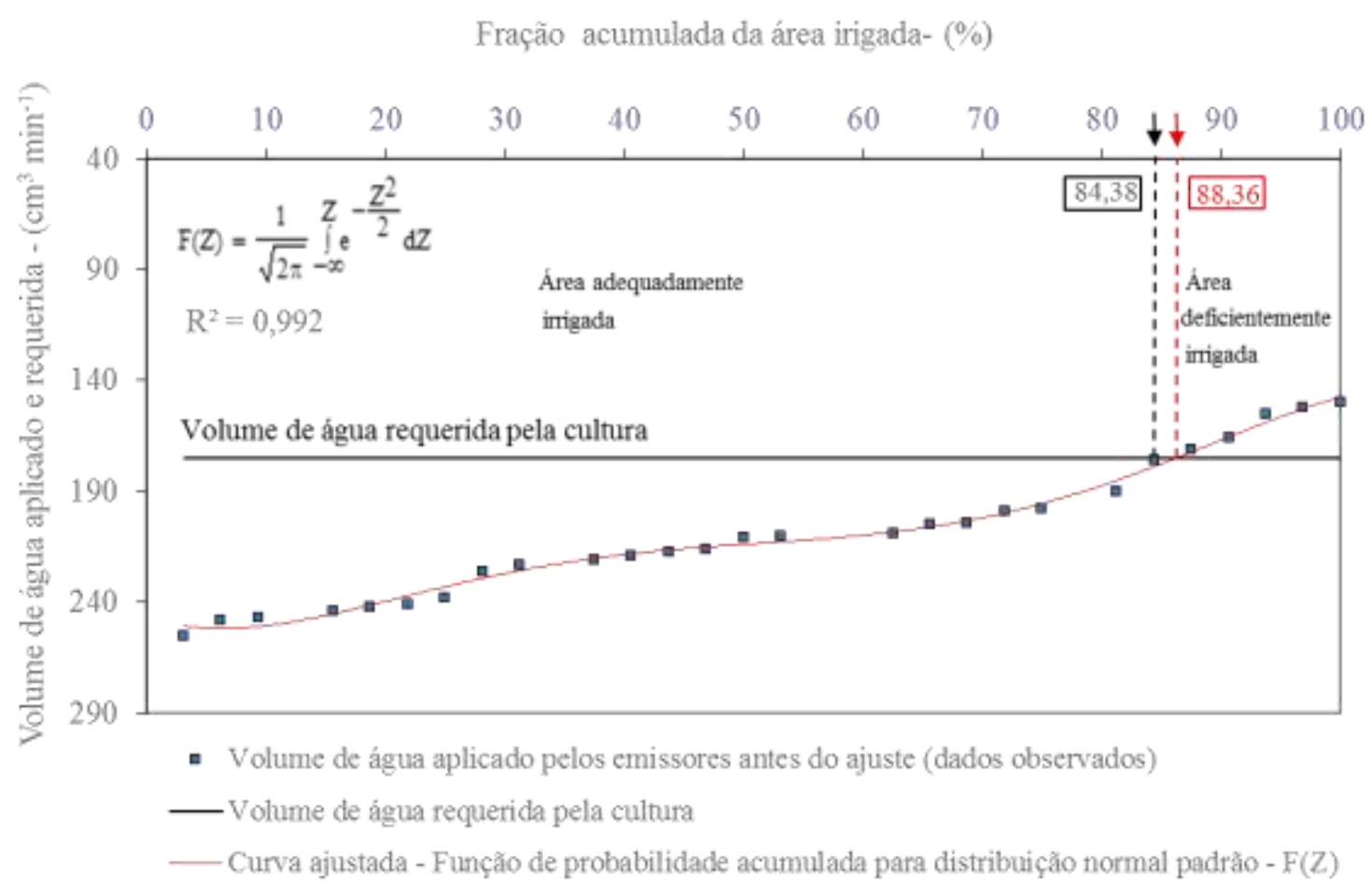

Fonte: Andrade et al. (2021).

Com referência à Figura 4, o limite da área adequadamente irrigada é representado pelas linhas verticais tracejadas, a azul para os dos dados observados e a de cor vermelha para a curva ajustada a distribuição acumulada normal padrão. Essas linhas dividem a fração de área acumulada em duas partes: à esquerda da linha, o perfil de distribuição de água que satisfaz o volume de água requerida pela cultura (área adequadamente irrigada), à direita o perfil de distribuição da área irrigada deficitariamente. Logo abaixo da área adequadamente irrigada, existe uma área irrigada com excesso de água, perdida por percolação profunda e/ou drenagem superficialmente para fora dos limites da área cultivada.

$\mathrm{O}$ valor $\mathrm{F}_{\mathrm{ac}}$, em que ocorre a divisão entre a área adequadamente e deficientemente irrigada, é denominada de grau de adequação da área irrigada $(\mathrm{Gad})$, que representa o percentual da área irrigada adequadamente. Sua determinação é efetuada de forma não analítica, tomando-se como base a distribuição de fração da área irrigada acumulada, conforme representado na Figura 4, pela intersecção das linhas perpendiculares tracejadas verticais azul (dados observados) e vermelha (valores estimados) até o ponto de intersecção entre a linha horizontal do volume de água necessário para a cultura $\left(\mathrm{V}_{\mathrm{r}}=175 \cdot \mathrm{cm}^{3} \cdot \mathrm{planta}^{-1} \mathrm{~min}^{-1}\right)$ e a curva se ajusta à distribuição cumulativa normal padrão.

Conforme indicado na Figura 4, observa-se que os valores do Gad foram de 84,38 e 88,36\% para os dados observados e pela curva ajustada pela distribuição acumulada normal padrão pelo MPNL, respectivamente. Isto significa que 84,38 e 88,36 \% da área irrigada receberam volume de água igual ou superior a $175 . \mathrm{cm}^{3} \cdot$ planta ${ }^{-1} \mathrm{~min}^{-1} \mathrm{e}$, indicando que apenas $15,62 \mathrm{e} 11,64 \%$, da área, foi insuficientemente irrigada, respectivamente.

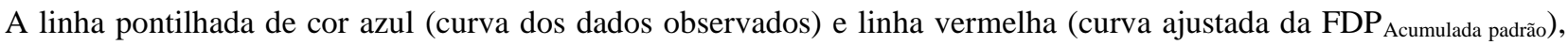
correspondente à lâmina de irrigação, delimita claramente as áreas nas quais foram a base para os determinados parâmetros de avaliação de eficiência de irrigação por meio da curva ajustada não linear do modelo da FDP Acumulada padrão (Figura 4). 
A integração das áreas irrigadas adequadamente, deficitária e excessivamente, permitiu calcular os parâmetros da eficiência de aplicação de água do sistema irrigação em função da vazão do emissor, obtendo-se os seguintes valores: volume de água médio aplicado na área $\left(\mathrm{V}_{\mathrm{a}}\right)$ de 209,56 $\mathrm{cm}^{3} \mathrm{~min}^{-1}$ (dois emissores por planta) com desvio padrão (DP) de $29,23 \mathrm{~cm}^{3} \mathrm{~min}^{-1}$, valor da variável reduzida $(\alpha)$ igual a -1,0899 adimensional, valor da adequação do modelo (a) de 0,8836, que corresponde ao valor da área adequadamente irrigada do sistema, e a área deficitária pela diferença de 1-F(Z), resultando no valor de 0,1164. A partir desses valores, $\alpha$, a e 1-F(Z), os valores do volume de água disponível em cada parcela da área de irrigação foram calculados utilizando as Equações 5 a 10: o volume de água disponível à cultura ou área adequadamente irrigada (A), o volume de água percolada ou excesso de água (B), o volume de água em disponibilidade na área irrigada deficitariamente (C) e o volume déficit (D), respectivamente, cujos valores foram 159,56; 32,10; 13,42 e 4,48 da fração da área acumulada $\left(\mathrm{F}_{\mathrm{ac}}\right)$ que recebe o volume de aplicação de água dos emissores.

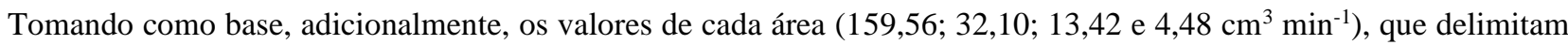
claramente as áreas que definem a eficiência de aplicação de água do sistema de irrigação, os parâmetros de eficiência referentes à avaliação do sistema de irrigação por gotejamento foram determinados analiticamente, através das Equações de 11 a 15 , considerando para o cálculo os valores do volume aplicado pelos dois emissores para o tempo de coleta de 5 minutos. Os resultados são apresentados de maneira resumida na Tabela 5 .

Tabela 5. Parâmetros de avaliação de eficiência do sistema de irrigação por gotejamento em cultivo de maracujá, por meio modelo probabilístico não linear (MPNL). Fonte: Andrade et al. (2021).

\begin{tabular}{ccccc}
\hline \multicolumn{5}{c}{ Parâmetros de eficiência do sistema de irrigação pelo modelo probabilístico não linear (MPNL) } \\
\hline Ea & Es & Pp & Gd & Gad \\
$-84,56$ & 97,90 & 15,44 & 2,10 & 88,36 \\
\hline
\end{tabular}

Fonte: Andrade et al. (2021).

Para a eficiência de aplicação ou distribuição de água do sistema do presente estudo (Ea), foi obtido um valor de 84,56\%, valor dentro dos padrões adequados de desempenho dos emissores para um sistema de irrigação por gotejamento de acordo com a ASAE (1996). A Es foi alta, indicando alto armazenamento de água na zona radicular. O Pp foi baixo, indicando baixas perdas de água por percolação. Como a adequabilidade da irrigação se refere à fração da área que recebe água suficiente para manter a produtividade em um nível econômico satisfatório e o valor encontrado foi de 88,36\%, mostra que a área está recebendo um volume superior à lâmina de água requerida pela cultura $\left(175 \mathrm{~cm}^{3}\right.$. planta-1 $\left.\mathrm{min}^{-1}\right)$.

De acordo com Frizzone et al. (2012) o parâmetro que melhor representa a adequabilidade do sistema de irrigação é o grau de adequação $(\mathrm{Gad})$ onde o valor encontrado foi alto $(85,36 \%)$, causando alto valor na eficiência de aplicação em decorrência do alto grau de adequação, por outro lado, diminui o $\mathrm{Gd}(2,10 \%)$ que é satisfatório para o sistema de irrigação. Segundo Soccol et al. (2002) o grau de adequação foi proposto para expressar o quanto o sistema de irrigação satisfaz, em termos de fração de área que está recebendo água, da condição de estar em conformidade com as necessidades da cultura, para manter a qualidade do produto e a produtividade da planta em um nível econômico. De acordo com Silva et al. (2002) a eficiência de aplicação de água em uma área irrigada expressa a relação percentual entre o volume de água efetivamente disponibilizado à planta, na zona de efetividade de seu sistema radicular, aqui denominado volume útil, e o volume total de água aplicado pela irrigação. Referindo-se às Figuras 1 e 4, o volume útil corresponde à soma da área adequadamente irrigada, sem excedente, com a área indicada como deficiente. Ou seja, toda água incorporada acima da área delimitada pela linha tracejada, representativa da lâmina média aplicada, deve ser considerada água útil. 
Finalmente, foi verificada a qualidade (validação) do MPNL, por meio da Figura 5 (Scatterplot) que representa a relação entre os valores do $V_{a}$ dos dados observados e os valores de $V_{a}$ estimados pelo modelo MPNL. A Figura 5 também mostra a equação da regressão, o coeficiente de correlação (r), o índice de concordância (d) e desempenho (C), que avalia a validação do ajuste do modelo probabilístico aos dados observados. A linha tracejada com vermelho representa a reta 1:1 onde os valores observados de $\mathrm{V}_{\mathrm{a}}$ são idênticos aos estimados de $\mathrm{V}_{\mathrm{a}}(\mathrm{Y}=\mathrm{X})$ e a linha tracejada azul mostra a regressão linear que descreve os valores observados $\left(Y=\beta_{1}+\beta_{2} X\right)$. Quanto mais próximas estão as duas linhas tracejadas e quanto mais os valores observados estão distribuídos em torno da reta 1:1 e bem alinhados em torno da equação linear (os pontos acompanharem um padrão linear), com valor alto de coeficiente de determinação $\left(\mathrm{R}^{2}\right)$ ao nível de significância de $\alpha \%$, podemos assegurar que o MPNL é consideravelmente satisfatório para estimar valores do $\mathrm{V}_{\mathrm{a}}$.

Figura 5. Comparação entre os valores observados do volume de água aplicado pelos emissores $\left(\mathrm{V}_{\text {ao }}\right)$ e os estimados $\left(\mathrm{V}_{\mathrm{ae}}\right)$ pelo modelo probabilístico não linear (MPNL) através da distribuição de probabilidade acumulada normal padrão (FDP Acumulada padrão) para sistema de irrigação por gotejamento em cultivo de maracujá. Fonte: Andrade et al. (2021).

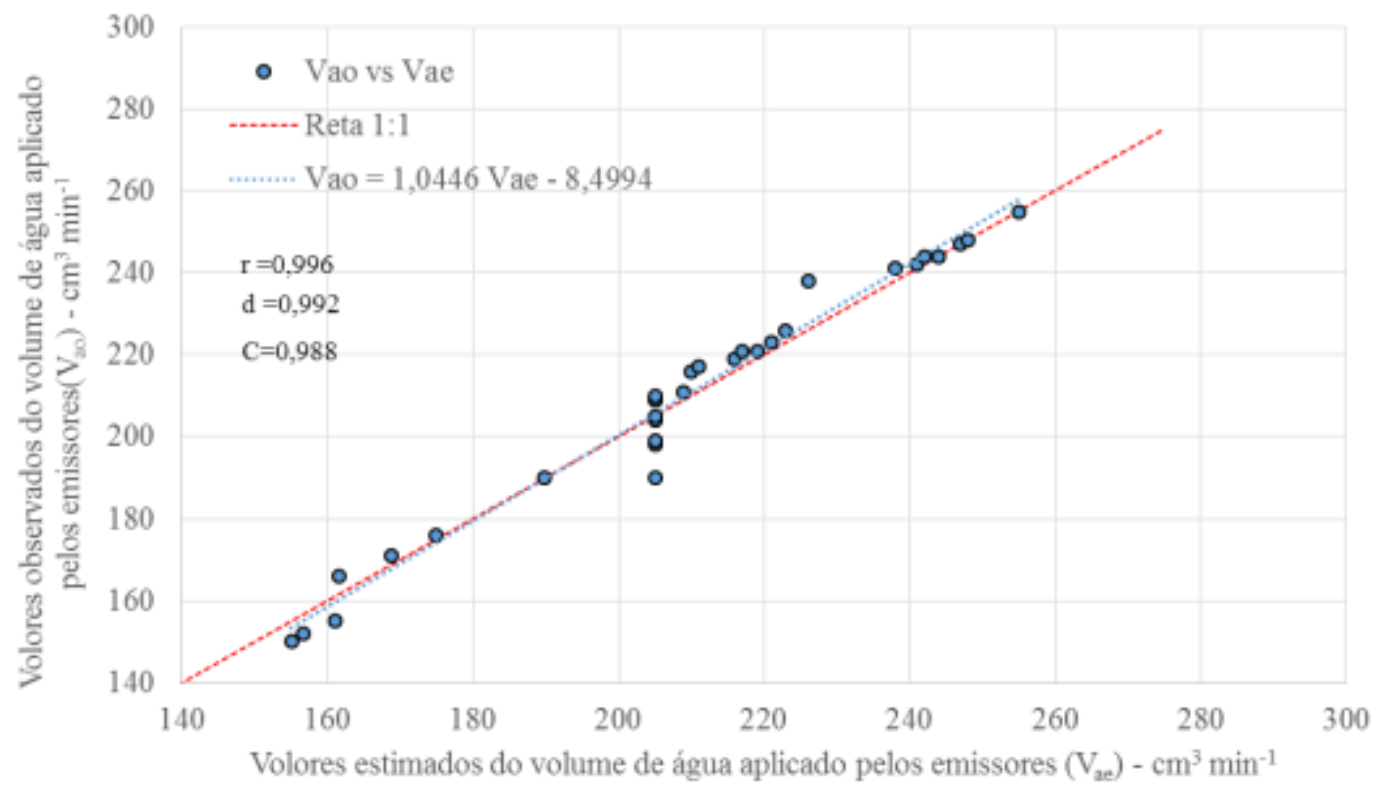

Fonte: Andrade et al. (2021).

Pela Figura 5, verifica-se que tantos os valores observados da fração acumulada da área irrigada quanto os valores calculados pelo modelo não-linear da distribuição normal acumulada são poucos dispersos e bem alinhados em torno da reta 1:1, que indica um excelente grau de ajuste dos dados observados do modelo probabilístico. Esse resultado também indica que o modelo não-linear da distribuição acumulada normal padrão apresenta a funcionalidade matemática necessária ao ajuste aos valores reais do volume de água coletado dos emissores pelos testes realizados em campo, e consequentemente na estimativa dos parâmetros de eficiência referentes para avaliação do sistema de irrigação por gotejamento. A adequação da concentração ao redor da reta 1:1 e da equação linear é confirmada pelos índices de concordância (d) e desempenho (C) iguais a 0,992 e 0,988 respectivamente, os quais, de acordo com a escala de Camargo e Sentelhas (1997), correspondem à classificação do tipo ótimo $(\mathrm{d}>0,76$ e $\mathrm{C}>0,85)$.

Comparando-se a reta 1:1 com a linha do ajuste através da distribuição de probabilidade acumulada normal padrão


realizados em campo, ou seja a subestimar valores de $V_{a}$. Observa-se que o MPNL utilizado para estimativa do $V_{a}$ apresentaram 
coeficientes angulares $\left(\beta_{2}\right)$ acima de 1, indicando uma tendência de subestimação dos valores de $V_{a}$ em relação aos observados nos ensaios de campo.

O coeficiente de determinação $\left(\mathrm{R}^{2}=0,992\right)$ que indica a precisão do ajuste da equação linear, entre valores observados e estimados do $\mathrm{V}_{\mathrm{a}}$, apresenta valor próximo a 1, concluindo-se que o modelo é consideravelmente explicado pela variável preditora. Isto indica que o modelo pode ser utilizado para fazer estimativas da $\mathrm{V}_{\mathrm{a}} \mathrm{e}$ dos parâmetros de eficiência de aplicação de água do sistema de irrigação.

O gráfico scatterplot dos resíduos padronizados, apresentado na Figura 6, mostra que os pontos de emissão dos gotejadores estão espalhando sem nenhum comportamento ou tendência, (sem comportamento cônico) e portanto temos indícios de que a variância dos resíduos é homoscedástica, ou seja, variância do erro experimental ( $\varepsilon$ ) para observações distintas constante e independente concluindo que MPNL é aceitável para estimar valores de Va e conseguintemente os parâmetros de eficiência de aplicação de água do sistema de irrigação localizada. Pode-se observar que $95 \%$ das diferenças residuais estão no intervalo de 1,5 a 1,5. Segundo (Maciel, 2019) um modelo bem ajustado aos valores dos resíduos são dispersos aleatoriamente em torno de zero, com variância constante, concentrados entre -2 e 2 e poucos pontos acima de 3 ou abaixo de -3 . Porém, observa-se que a distribuição dos resíduos apresenta uma moderada assimetria, bem como a presença de alguns resíduos extremos (valores dos resíduos abaixo de -1,5 e acima de 1,5) que correspondente aos ponto de emissão: L4E1P1 e L2E2P3/3 que são considerados atípicos, e que pelo teste gráfico Q-Q plot (Figura 2), não foram validados como atípicos.

Figura 6. Gráfico Scatterplot dos resíduos padronizados, das diferenças entre os valores observados da Va e estimados pelo modelo probabilístico não linear (MPNL) através da distribuição de probabilidade acumulada normal padrão (FDP Acumulada padrão), para sistema de irrigação por gotejamento em cultivo de maracujá.

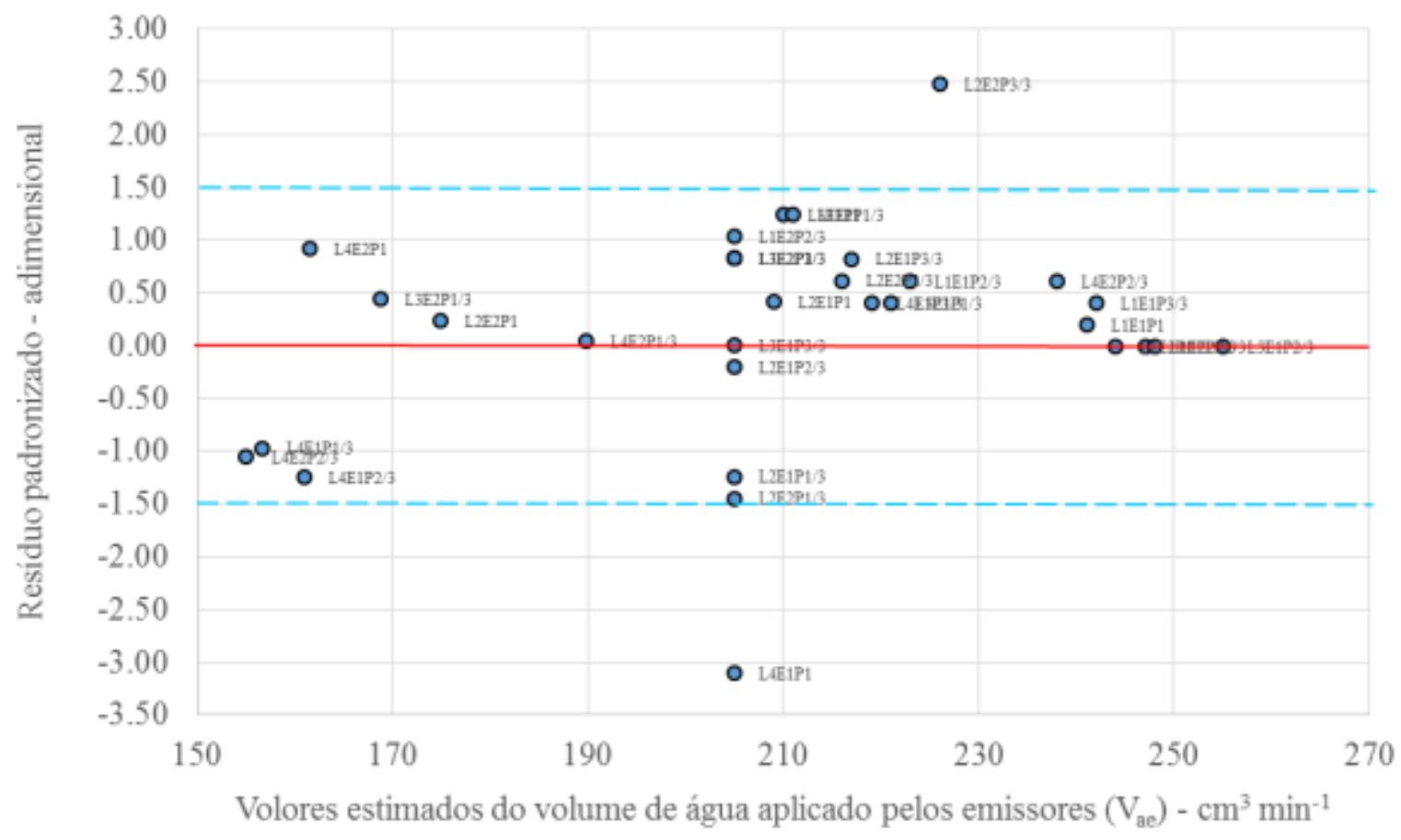

Fonte: Andrade et al. (2021).

\section{Avaliação da eficiência do sistema de irrigação por gotejamento através do modelo de regressão não linear - MRNL}

Os resultados apresentados na Figura 7 mostram que a melhor equação ajustada foi a equação polinomial do terceiro grau, apresentando um valor de $\mathrm{R}^{2}$ de 0,984 , indicando um bom ajuste do MRNL, ou seja, 98,40\% da incerteza original dos 
dados foi explicada pelo modelo polinomial, e que a proporção da variabilidade de estrutura que não pode ser explicada pela variabilidade é de apenas 5,6\%. Portanto, pode-se assumir que o modelo polinomial explica uma quantidade significativa da variação da $V_{a}$ em função da variabilidade da $F_{a c}$. Temos que a correlação entre as variáveis é de 99,19\%, indicando uma forte relação linear entre as variáveis $\mathrm{V}_{\mathrm{a}}$ e $\mathrm{F}_{\mathrm{ac}}$, ou seja, as variáveis são estatisticamente dependentes.

Figura 7. Curva de ajuste da regressão polinomial do terceiro grau dos volumes de água coletado dos emissores $\left(\mathrm{V}_{\mathrm{a}}\right)$ em função da fração acumulada da área irrigada $\left(\mathrm{F}_{\mathrm{ac}}\right)$, do sistema de irrigação por gotejamento em cultivo de maracujá.

Fração acumulada da área irrigada - (\%)

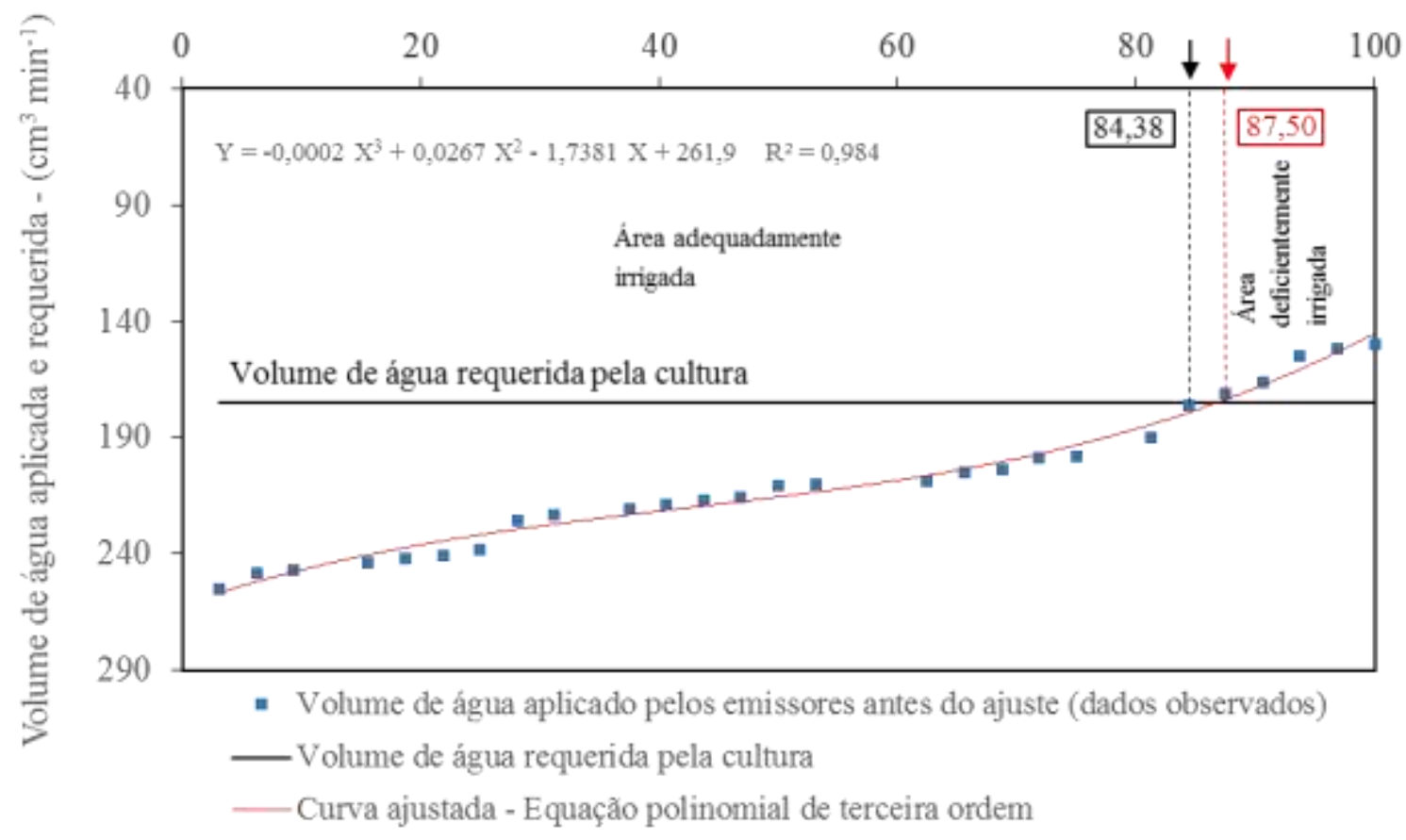

Fonte: Andrade et al. (2021).

Aplicado o teste "t", verificou-se que todas as estimativas dos parâmetros $\left(\beta_{o}, \beta_{1}, \beta_{2}\right.$, e $\left.\beta_{3}\right)$ estimados pelo do método dos mínimos quadrados, são significativas explicativos ( $\mathrm{p}$-valor $\leq 0,0015)$, indicando que a variável independente $\left(\mathrm{F}_{\mathrm{ac}}\right)$ contribuí satisfatoriamente para a construção do modelo polinomial, fato reforçado pelo coeficiente de determinação $\left(R^{2}=0,984\right)$, mostrando o quanto da variação dos valores da variável dependente $\left(\mathrm{V}_{\mathrm{a}}\right)$ é explicada, em parte, pela variação da variável independente que é representada pelos valores das $\mathrm{F}_{\mathrm{ac}}$. Além do testes $\mathrm{F}$ da análise da variância da regressão (ANOVA do modelo de regressão), indica que o modelo é significativamente explicado pela variável independente ao nível de $\alpha=5$ e $1 \%$ (p-valor $\leq$ 0,000), e mostra a consistência do modelo polinomial. Pela Figura 7, o modelo de regressão polinomial do terceiro grau ficou assim representados: $\mathrm{V}_{\mathrm{a}}=-0,0002\left(\mathrm{~F}_{\mathrm{ac}}\right)^{3}+0,0267\left(\mathrm{~F}_{\mathrm{ac}}\right)^{2}-1,7381 \mathrm{~F}_{\mathrm{ac}}+261,90$.

Para a utilização do modelo polinomial, foi necessário verificar o pré-requisito de normalidade dos resíduos gerados do modelo polinomial ajustados. Para tanto, foram aplicados os testes Shapiro-Wilk (SW) e os testes gráfico do diagrama Q-Q plot normal e P-P plot para os resíduos.

Observa-se na Figura 7 que, de modo geral, a regressão do modelo polinomial do terceiro grau representou adequadamente a distribuição de água aplicada pelos emissores "gotejadores". Observa-se também que o modelo polinomial representou pequena discrepância entre os valores do volume de água simulados pelo modelo e observados (dados amostrais) obtidos dos ensaios realizados em campo com do sistema de irrigação localizado, isto pode ser confirmado pelo teste Shapiro- 
Wilk $(\mathrm{SW})$ onde, pelo valor SW (calculado) $=0,8902$ maior que SW (tabelado) $=0,7611$ (p-valor $>0,01$ ) com grau de probabilidade (GL) de 32 e a nível de significância de $1 \%$, indica a boa aderência do modelo aos dados observados.

Na Figura 8 apresenta a relação entre os quantis teóricos do MRNL por meio da regressão polinomial do terceiro grau e dos dados empíricos das distribuições amostrais dos valores variáveis dependentes $\mathrm{V}_{\mathrm{a}}$ em função de $\mathrm{F}_{\mathrm{ac}}$. Observa-se que, quanto mais os pontos se aproximam da reta da equação linear melhor, precisão do grau de ajuste do modelo. O que se espera de um modelo em relação ao grau de ajuste é valor de $\mathrm{R}^{2}$ seja o mais próximo possível de 1 , que o valor de os desvios seja o mais próximo possível de zero e que os resíduos apresentem distribuição normal em torno de zero (Capp \& Nienov, 2020).

Figura 8. Diagrama Q-Q plot para avaliação da adequação do modelo e da normalidade dos resíduos dos valores do volume de água aplicado pelos emissores $\left(\mathrm{V}_{\mathrm{a}}\right)$ pelo sistema de irrigação por gotejamento em cultivo de maracujá por meio do modelo de regressão não linear (MRNL).

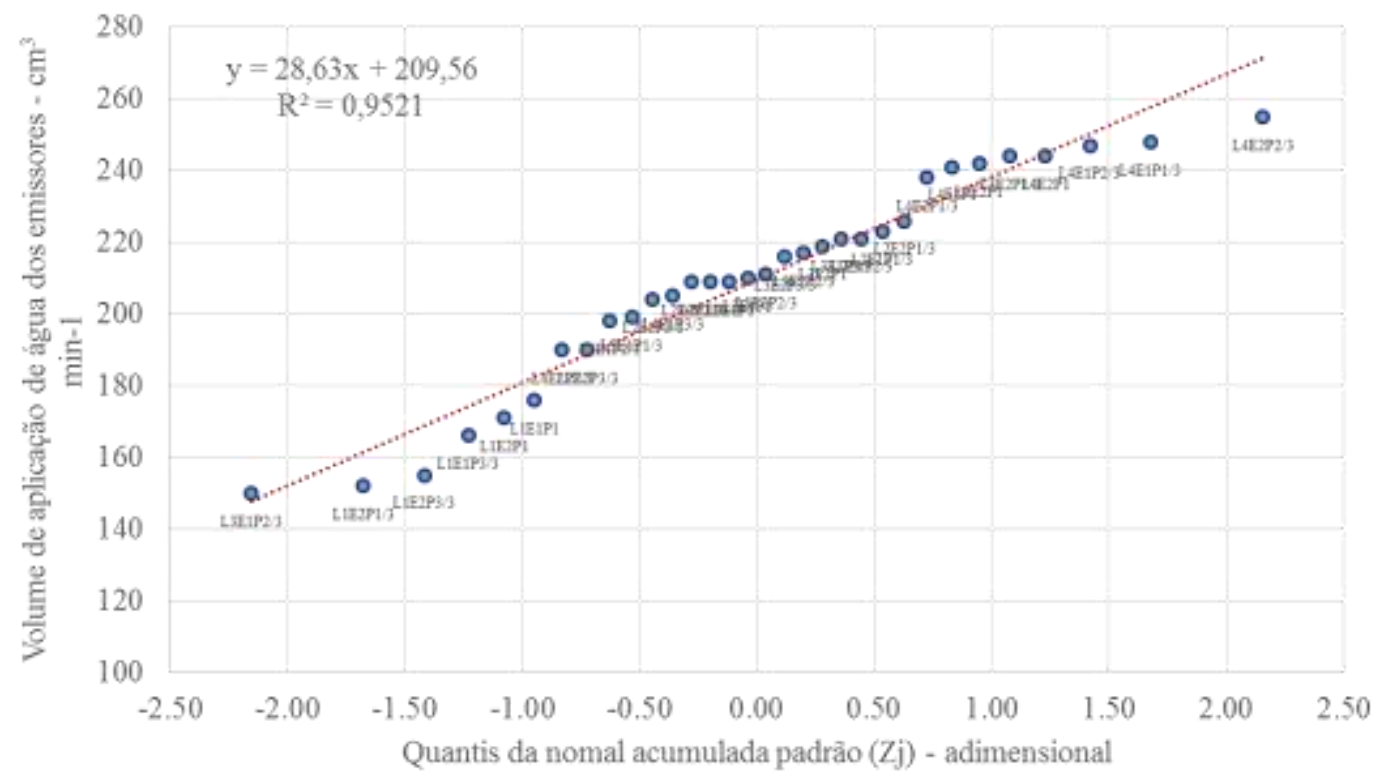

Fonte: Andrade et al. (2021).

Verifica-se pelo diagrama Q-Q plot que existem pontos poucos dispersos e bem alinhados em torno da equação linear (os pontos seguem um padrão linear), com valor elevado do coeficiente de determinação ( $R^{2}$ ) de 0,9755 ao nível de significância de $1 \%$, evidenciando a normalidade dos dados observados, e conclui-se que o MRNL por meio do ajuste da equações polinomial do terceiro grau serve como um modelo plausível para explicar e descrever a distribuição dos dados observados ( $\mathrm{V}_{\mathrm{a}}$ ) (Figura 8). No gráfico Q-Q plot, uma a diferença significativa é observada entre os valores do $\mathrm{V}_{\mathrm{a}}$ nos seguintes pontos de emissão: L1E2P1/3, L1E2P3/3, L4E1P1/3 e L4E2P2/3, pontos esses iguais aos constados no gráfico Q-Q plot para o MPNL (Figura 2). Ainda pela Figura 8, observam-se lacunas abertas em torno da origem e ao final da curva dos valores de quantis, denominado "gaps", indicando a presença de valores discrepantes nos dados. Esses valores extremos podem introduzir viés no modelo, afetando os valores dos coeficientes de regressão estimados e nos parâmetros de avaliação de eficiência de aplicação de água pelo sistema de irrigação.

Outra forma de avaliar graficamente o ajuste da distribuição é usar os gráficos de probabilidades (P-P plot) da Figura 9. Neste caso, o ajuste dos dados pode ser comparado em termos da probabilidade acumulada, comparando a função de distribuição acumulada empírica e a função de distribuição acumulada do modelo (ajustada). Nesta Figura, observam-se os pontos alinhados 
em uma reta indicando um bom ajuste do modelo de regressão. Essa boa aderência do modelo foi confirmada pelo teste de Shapiro-Wilk ao nível de significância de $1 \%$.

Figura 9. Diagrama P-P plot para avaliar a adequação do modelo e da normalidade dos resíduos dos valores do volume de água aplicado pelos emissores $\left(\mathrm{V}_{\mathrm{a}}\right)$ pelo sistema de irrigação por gotejamento em cultivo de maracujá por meio do modelo de regressão não linear (MPNL). Fonte: Andrade et al. (2021).

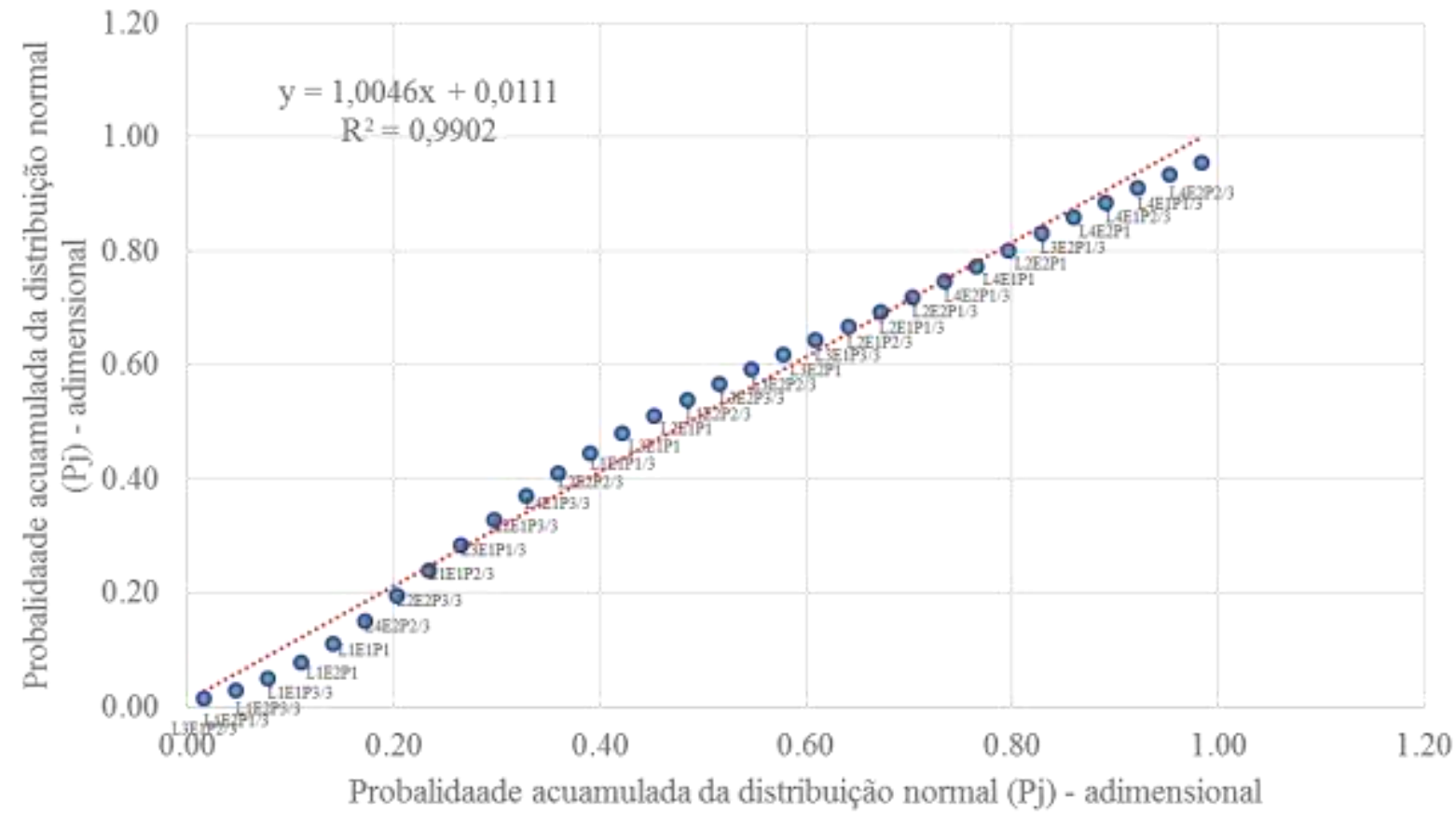

Fonte: Andrade et al. (2021).

Após o ajuste do MRNL e ter realizados os devidos testes quanto à adequação do modelo e a normalidade dos resíduos, contendo $\mathrm{V}_{\mathrm{a}}$ como variável dependente e a $\mathrm{F}_{\mathrm{ac}}$ como variável independente, foram determinados os valores das áreas que representam os volumes de água disponível à cultura ou área adequadamente irrigada (A), o volume de água percolada ou excesso de água (B), o volume de água em disponibilidade na área irrigada deficitariamente (C) e o volume déficit (D), respectivamente, foram calculados e cujos valores encontrados foram 15.312,50; 3.919,36; 2.187,50 e 2.167,64 da fração da área acumulada $\left(\mathrm{F}_{\mathrm{ac}}\right)$ que recebe o volume de aplicação de água dos emissores.

Com base nos valores dos coeficientes do modelo de regressão polinomial ajustados aos dados, do valor Va (175 $\mathrm{cm}^{3}$.planta $\left.{ }^{-1} \mathrm{~min}^{-1}\right)$ e dos valores do volume de água em disponibilidade na parcela da área irrigada (A, B, C e D), foram calculados os parâmetros de eficiências de aplicação de água referentes à avaliação do sistema de irrigação por gotejamento por meio do MRNL, através das equações de 21 a 25, onde os valores são apresentados de maneira resumida na Tabela 6.

Tabela 6. Parâmetros de avaliação de eficiência do sistema de irrigação por gotejamento em cultivo de maracujá, por meio do modelo estatístico de regressão (MRNL). Fonte: Andrade et al. (2021).

\begin{tabular}{cccc}
\hline \multicolumn{4}{c}{ Parâmetros de eficiência do sistema de irrigação pelo modelo de regressão não linear - MRNL } \\
\hline Ea & Es & Pp & Gd \\
81,68 & 99,88 & 16,92 & Gad \\
-
\end{tabular}

Fonte: Andrade et al. (2021). 
Para a eficiência de aplicação ou distribuição de água do sistema do presente estudo (Ea), obteve-se valor de 81,68\%, valor este que está dentro dos padrões de classificação de desempenho dos emissores para um sistema de irrigação por gotejamento de acordo com ASAE (1996), a eficiência de armazenamento (Es = 99,88\%), perdas por percolação ( $\mathrm{Pp}=16,92 \%)$, grau de déficit $(\mathrm{Gd}=0,11 \%)$ e grau de adequação $(\mathrm{Gad}=87,50 \%)$. Verifica-se que, o valor da Ea é satisfatório para um método de irrigação por gotejamento, cujo ideal seria um valor superior 80\% (Keller \& Bliesner, 1990). Entretanto, Es e a Pp foram elevados, indicando alto armazenamento de água na zona radicular e um volume considerável de água perdida por percolação profunda.

A transição entre as áreas adequadamente irrigada e deficientemente irrigada é definida por a Gad que determina o ponto de interseção entre o descrito pelo modelo e a linha cheia de cor preta correspondente ao valor do $\mathrm{V}_{\mathrm{r}}$. $\left(175 . \mathrm{cm}^{3}\right.$.planta ${ }^{1} \mathrm{~min}^{-1}$ ). Segundo Silva et al. (2004) a área adequadamente irrigada é uma operação na qual se busca o ponto ótimo entre o porcentual de área que deve receber aplicações de água em quantidades iguais ou superiores à lâmina requerida pela cultura para atender às necessidades de produtividade, com o menor porcentual de excesso possível. A água aplicada em excesso representa aumento no consumo de energia, reduzindo a margem de lucro do produtor, com possíveis impactos na lixiviação de nutrientes e o meio ambiente. Por outro lado, a inadequação na distribuição incorreta da água, que pode determinar baixos valores de eficiência de irrigação, pode levar a efeitos desfavoráveis como: baixa produtividade por área; baixa produtividade por unidade de água aplicada; diminuição da área total irrigada; efeitos prejudiciais ao meio ambiente e lucratividade menor com a agricultura irrigada (Schons, 2010).

Com base na Figura 7 e de forma gráfica, determinou-se Gad, chegando-se aos resultados 84,38 e 87,50 \% para os dados observados e ajustada pelo polinômio do terceiro grau (modelo estatístico de regressão), respectivamente. Isto significa que $84,38 \%$ (curva dos dados observados) e 87,50 \% (curva ajustada pela regressão polinomial) da área irrigada receberam volume de água igual ou maior que $175 \mathrm{~cm}^{3}$.planta ${ }^{-1} \mathrm{~min}^{-1}$, indicando que apenas 15,62 e 12,50\% da área foram irrigadas deficitariamente, respectivamente.

Dando sequência às análises de validação do modelo de regressão (MRNL), através do gráfico Scatterplot da Figura 10, que ilustra a reta 1:1 (reta de $45^{\circ}$ grau). Pode-se observar que o resultado da análise da regressão polinomial do terceiro grau ajustou-se aos dados observados. 
Figura 10. Comparação entre os valores observados do volume de água aplicado pelos emissores ( $\left.\mathrm{V}_{\mathrm{ao}}\right)$ e os estimados ( $\left.\mathrm{V}_{\mathrm{ae}}\right)$ pelo modelo de regressão não linear (MPNL) através do ajuste da equação polinomial do terceiro grau, para sistema de irrigação por gotejamento em cultivo de maracujá.

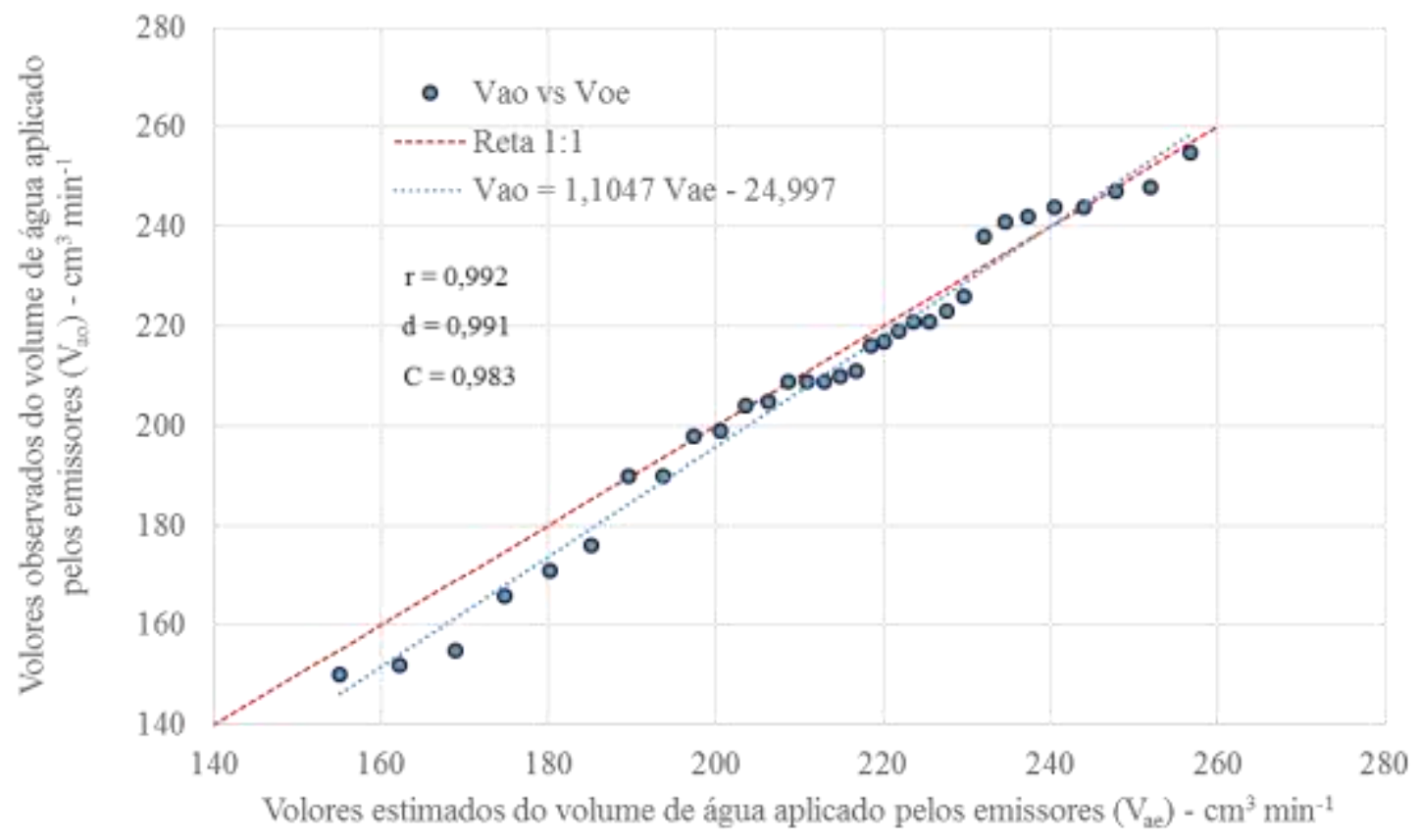

Fonte: Andrade et al. (2021)

Pela plotagem no plano bidimensional dos valores observados $\left(\mathrm{V}_{\mathrm{ao}}\right)$ e estimados da $\left(\mathrm{V}_{\mathrm{ae}}\right)$ e pela análise de regressão linear simples, com o ajuste da reta passando pela origem $(0,0)$, verifica-se que o desempenho do ajuste do MRNL apresentando um valor do coeficiente de correlação (r) igual a 0,992, enquanto o índice de concordância de Wilmontt (d), que mede a concordância ou similaridade entre os métodos, houve um ajuste bastante homogêneo entre as metodologias, todas permaneceu em torno de 0,991 e valor do índice de desempenho (C) igual a 0,983, indicando a performance da concordância entre valores observados e estimados (Figura 10), que, de acordo com a escala de Camargo e Sentelhas (1997), corresponde à classificação do tipo Muito Bom $(0,76 \leq \mathrm{C} \leq 0,85)$. Observa-se também que o modelo de regressão polinomial do terceiro grau apresentou coeficiente da equação polinomial abaixo de 1, indicando tendência de superestimação dos valores de $\mathrm{V}_{\text {a }}$ pelo MRNL.

A distribuição normal dos resíduos é essencial para que os resultados da validação do modelo de regressão sejam confiáveis. Através do gráfico scatterplot dos resíduos padronizados, apresentados na Figura 11, essa suposição pode se verificada por meio de uma inspeção visual. Se o modelo se ajusta bem aos dados da amostra, todos os resíduos devem ser aleatoriamente distribuídos, sem qualquer comportamento ou tendência e todos os resíduos são distribuídos em torno de zero. Caso o modelo não tenha uma boa aderência aos dados da amostra, os valores dos resíduos não são distribuídos aleatoriamente em torno de zero, com variância heterogênea, e com valores dos resíduos maiores que 1,5 e menores que -1,5. 
Figura 11. Gráfico Scatterplot dos resíduos padronizados das diferenças entre os valores observados da $V_{\mathrm{a}}$ e estimados pelo modelo de regressão não linear (MRNL) por meio da regressão polinomial do terceiro grau, para sistema de irrigação por gotejamento em cultivo de maracujá.

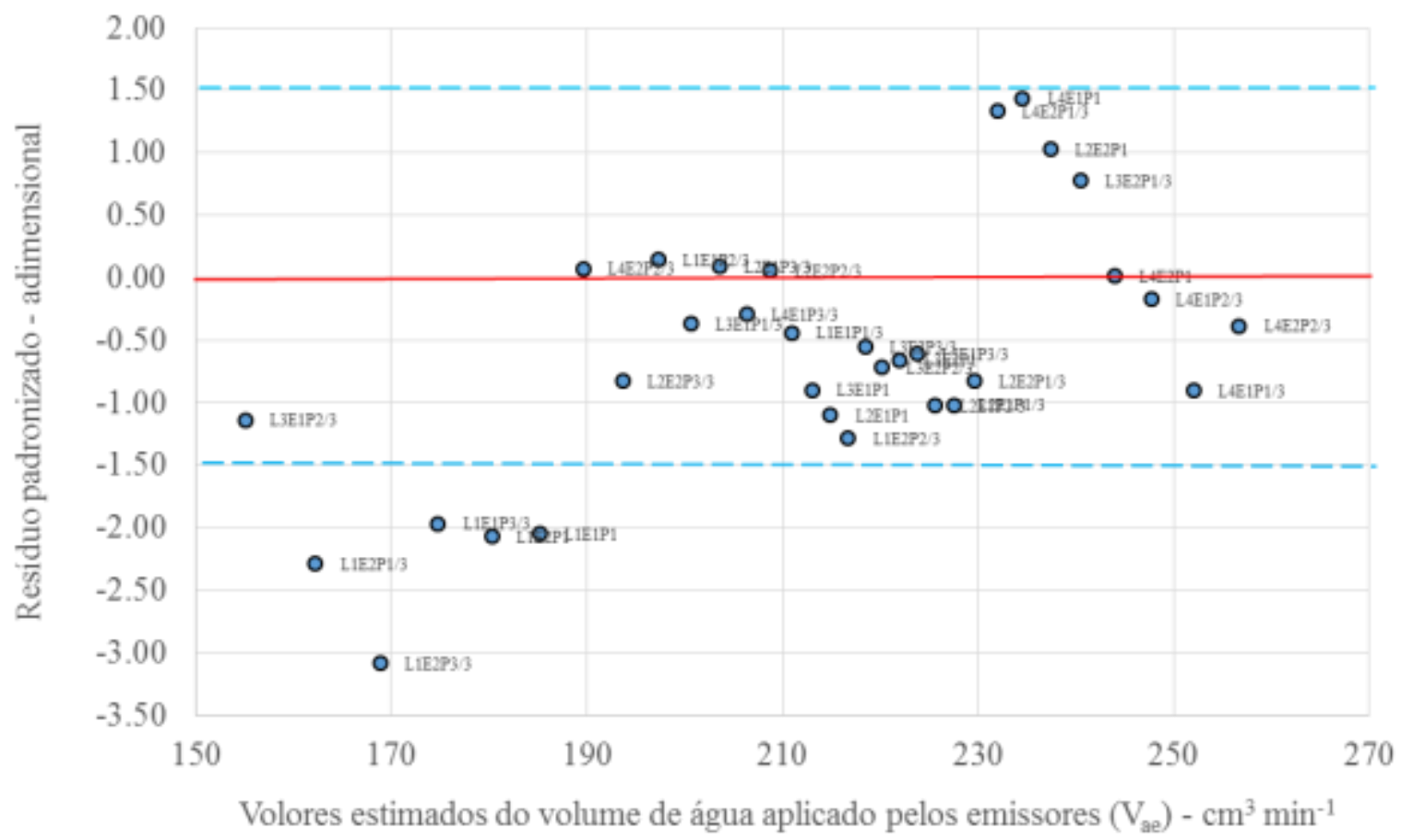

Fonte: Andrade et al. (2021).

De acordo com a Figura 11, pode-se observar que a distribuição dos resíduos segue de forma aleatória em torno do valor zero e sem nenhuma variação extrema ou concentração de valores em uma determinada área do gráfico "não apresenta nenhum padrão de comportamento ou tendência", então são aceitas as hipóteses de independência e variância constante dos resíduos. Assim, temos que a variável $\mathrm{F}_{\mathrm{ac}}$ está relacionada não linearmente com a variável $\mathrm{V}_{\mathrm{a}}$, ou seja, o ajuste do modelo MRNL é consideravelmente confiável para estimar valores de $\mathrm{V}_{\mathrm{a}}$ e conseguintemente os parâmetros de eficiência de aplicação de água do sistema de irrigação. Desta forma, o modelo inferido pode ser usado para estimar os valores de $\mathrm{V}_{\mathrm{a}}$ na área abrangida pela pesquisa.

Ainda pode-se observar na Figura 11, que 95\% dos resíduos estão no intervalo $(-1,5,+1,5)$, indicando condições favoráveis ao ajuste do modelo. Entretanto, observa-se que a distribuição dos resíduos apresenta uma moderada assimetria, bem como a presença de alguns resíduos elevados (valores dos resíduos abaixo de -1,5 e acima de 1,5) que correspondem aos pontos de emissão: L1E1P3/3, L1E1P3/3, L1E2P1, L1E2P1/3 e L1E2P3/3 que são considerados atípicos, e validado pelo teste gráfico Q-Q plot (Figura 8), exceção para o ponto de emissão: L4E1P1/3 e L4E2P2/3.

\section{Comparação dos resultados obtidos modelo matemáticos e propostos no estudo}

Visando uma melhor visão quanto aos resultados dos parâmetros de avaliação de eficiência do sistema de irrigação por gotejamento e para efeito de discussão da comparação dos resultados obtidos pelos três métodos propostos no estudo (MMP, MPNL e MRNL), os resultados das eficiências são resumidos na Tabela 7. 
Tabela 7. Comparação dos valores parâmetros de avaliação de eficiência do sistema de irrigação por gotejamento em cultivo de maracujá, por meio dos três métodos.

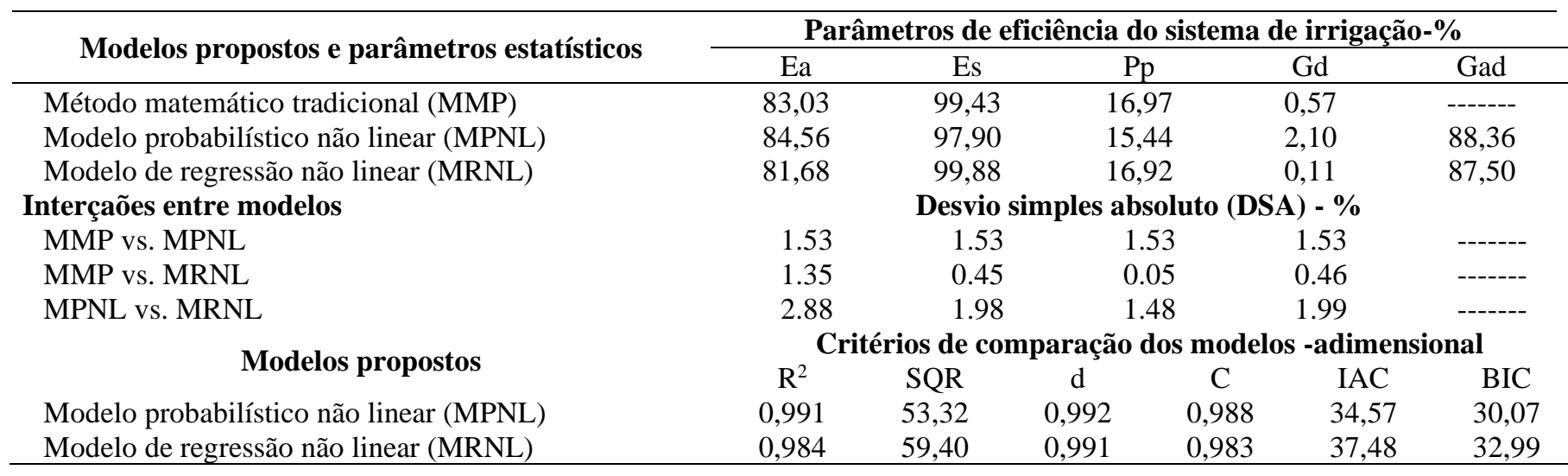

$\mathrm{R}^{2}=$ coeficiente de determinação; $\mathrm{SQR}=$ soma do quadrado do resíduo; d = índice de concordância de Willmott et al. (1985); C = pelo índice de confiança de desempenho; critério de informação de Akaike (AIC) e o critério de infromação Bayesiano (BIC). Fonte: Andrade et al. (2021).

Analisando-se a Tabela 7, é possível observar-se, pelos desvios simples absolutos (DSA) uma concordância aceitável entre os valores dos parâmetros determinados entre os modelos analisados, que variam da ordem de $0,05 \%$ a $2,88 \%$, Isto representa uma variação muito baixa, justificando-se assim a utilização da solução da análise de regressão não linear de qualquer uns dos modelos propostos, MPNL ou MRNL para a estimativa dos parâmetros de avaliação do sistema de irrigação por gotejamento.

Analisando a diferença entre os valores estimados e observados nos ensaios de campo, por meio dos valores da DSA, observou-se um melhor desempenho do MRNL em comparação com o MPNL para representar a distribuição dos valores dos parâmetros de avaliação do sistema de irrigação, visto que os valores do DSA foram iguais a 1,35\%, 0,45\%, 0,05\% e 0,46\% para os parâmetros Ea, Es, Pp e Gd, respectivamente comparados a 1,53\% para todos os parâmetros obtidos através do MPNL (Tabela 7). Os resultados obtidos neste estudo corroboram com os obtidos por Silva e Hart (1992) e Anyoji e Wu (1994) avaliando o sistema de irrigação por gotejamento. Os erros de estimativa pelo MPNL podem ser atribuídos a maior número de parâmetros do modelo e complexidade no processo de integração da função da distribuição de probabilidade acumulada normal para o cálculo da fração das áreas irrigadas necessárias para avaliação de eficiência de irrigação.

Entretanto, levando-se em consideração os critérios de qualidade de ajuste SQR, d, C, IAC e BIC, O modelo MPNL ajustou-se melhor aos valores de volume de água aplicado pelos emissores, uma vez que apresentaram os menores valores, conforme mostrado na Tabela 7. Deve-se destacar que o MPNL possui um AIC inferior ao modelo MRNL, isto ocorre devido ao emprego do efeito parametrizado no modelo. Por meio do índice de concordância (d) e desempenho (C), foi possível verificar a melhor representatividade dos dados simulados pelo MPNL, estando em concordância com os valores obtidos no teste gráfico Scatterplot dos resíduos padronizados (Figura 6), onde os resíduos dispersos aleatoriamente estão bem concentrados em torno de zero.

O teste $\mathrm{F}$ aponta que os dois modelos são significativamente válidos na utilização para o estudo (p-valor <0,001). Se a escolha do modelo for feita apenas pela observação do DSA, o modelo MRNL se ajustou melhor aos valores do $\mathrm{V}_{\mathrm{a}}$. Resultados semelhantes foram observados por Silva et al. (2009), onde revelaram que a função polinomial do quinto grau é a recomendada para descrever perfis de distribuição da água aplicada por sistemas de irrigação. Silva et al. (2006), recomendam o uso de modelos matemáticos não-lineares na análise de desempenho de sistemas de irrigação.

Em relação aos outros avaliadores de qualidade de ajuste (SQR), em geral, a curva da distribuição de probabilidade acumuladas normal apresentou melhores resultados para descrever perfis de distribuição da água aplicada por sistemas de 
irrigação e para derivar expressões matemáticas para o cálculo dos indicadores de desempenho correspondentes em comparação à função polinomial do terceiro grau.

Nesse mesmo contexto, Neto et al. (2015) com objetivo de identificar a aderência da distribuição normal de probabilidades às lâminas de água observadas em ensaios de campo em um sistema de irrigação por aspersão, concluíram que a distribuição normal apresentou o melhor ajuste, o autor também afirma que esta função pode ser utilizada para a determinar as parcelas da área irrigada que estão recebendo água em excesso ou em déficit, e, adicionalmente, para determinar o volume deste déficit ou perda, o que permite determinar a eficiência de um sistema de irrigação. Situação semelhante foi encontrada por Anyoji e Wu (1994), avaliando a distribuição normal de probabilidades em um sistema de irrigação por gotejamento, verificaram que esta distribuição representa adequadamente a lâmina de água aplicada por gotejadores. O autor na verdade reforça que a distribuição normal de probabilidade pode ser usada para descrever a lâmina de água aplicada por diferentes aspersores, bem como de diferentes sistemas de irrigação. Já Silva et al. (2004) propuseram um novo modelo matemático para análise de desempenho de sistemas de irrigação, relatando ter sido a formulação proposta emanada do modelo de retenção de água de Genutchen (1980) e indicaram que seu modelo apresentava a funcionalidade matemática necessária ao ajuste aos vários tipos de perfil de água aplicada pela irrigação.

A Tabela 7 mostra um comportamento muito próximo entre os modelos MPNL e MRNL, conforme indicado pelos valores obtidos, de 84,03\% para o Ea estimada pela distribuição normal e 81,68\% para o simulado pela regressão polinomial, com diferença real entre os valores de Ea de apenas 2,35\%. Embora o MRNL não seja amplamente utilizado, na descrição de eficiência de aplicação de água em sistema de irrigação é recomendada sua utilização na estimativa dos parâmetros de eficiência de aplicação de água como alternativa para distribuições tradicionalmente utilizadas. Dentre os que convergiram, nota-se que, de maneira geral, o ajuste entre $\mathrm{V}_{\mathrm{a}}$ e $\mathrm{F}_{\mathrm{ac}}$ em ambos os modelos, MPNL e MRNL, como pode ser visto respectivamente nas Figuras 5 e 10 e na Tabela 7, se destacam pela facilidade de interpretação e aplicação, e também apresenta elementos práticos para avaliação do sistema, como, por exemplo, o grau de adequação $\left(\mathrm{G}_{\mathrm{ad}}\right)$ que expressa a porcentagem de área adequadamente irrigada, embora que o modelo MRNL tenha apresentado uma melhor qualidade no ajuste aos dados observados em campo, e portanto, os valores dos parâmetros de eficácia de aplicação de água mais próximo do modelo padrão, MMP.

Utilizando a metodologia do MRNL, verifica-se que o parâmetro Ea teve apenas um aumento da ordem de 1,816\% em seu valor quando comparado ao MMP, melhorando assim, a performance do sistema de irrigação. Como os valores de eficiência de aplicação encontrados foram elevados, constatou-se que a irrigação foi realizada com alto grau de adequação, resultando em pequena fração da área irrigada com déficit de água. Embora a eficiência de aplicação de água em um sistema de irrigação seja indicador do excesso de água aplicada, não dá ideia do reabastecimento da zona radicular. A eficiência de armazenamento constitui o indicador desse reabastecimento. Os valores de armazenamento (Es) para os modelos foram altos, verificando uma leve redução da Es no valor de 1,53\% do MRNL em relação ao MMP e aumento de 0,45\% da Es do MPNL em comparação com o modelo padrão. Como a Es é um parâmetro que define a fração da quantidade de água necessária para suprir o déficit onde está armazenada parte do sistema radicular da cultura, foram observados elevados valores de eficiência de armazenamento para os dois modelos estudados, indicando um excesso de irrigação, resultando em considerável perda por percolação. De acordo com Paulinho et al. (2009), a inadequada uniformidade de aplicação de água nos sistemas de irrigação proporciona excesso da mesma em parte da área de cultivo e falta em outra, reduzindo a disponibilidade de água para a cultura e aumentando o custo de produção.

As perdas por percolação foram bastante significativas, tanto para o MMP, de 16,97\%, quanto para os modelos MPNL e MRNL, com valores iguais a 15,44 e 16,92\%, respectivamente, mas tais perdas por percolação e grau de déficit diminuíram com o uso do MRNL por aproximadamente $9,01 \%$. Ao comparar os modelos MPNL e MRNL no quesito área adequadamente irrigada, verifica-se uma diferença da ordem 2,86\% com destaque para o MRNL com valor de $\mathrm{G}_{\text {ad }}$ igual a 88,36\%. Este fato pode 
ser explicado pela redução da perda de água por percolação profunda, considerada ideal para o sistema de irrigação que, por disponibiliza mais água na zona radicular.

Diante dos resultados encontrados com a metodologia simplificada, a proposta para avaliação do sistema de irrigação, mostrou-se bastante eficiente, comprovada pelos testes realizados, podendo o responsável técnico pela condução da irrigação na propriedade proceder à coleta de dados e, por meio dos modelos MPNL e MRNL, verificar como está funcionando o sistema de irrigação. Além disso, as duas funções propostas representadas pela distribuição acumulada normal padrão e polinomial do terceiro grau podem ser facilmente adaptada aos recursos de planilhas eletrônicas para obter os parâmetros de ajuste, expandindo assim as possibilidades de melhor ajuste ao representar a grande variedade de perfis de distribuição normalmente observados em avaliações de desempenho de sistemas de irrigação.

\section{Conclusões}

Após a utilização dos modelos de estimativa dos parâmetros de avaliação de eficiência do sistema irrigação por gotejamento em cultivo de maracujá, concluiu-se que:

1) Os três modelos utilizados nesta pesquisa (MMP. MPNL e MRNL), apresentaram ótimo desempenho na estimativa dos parâmetros que determinam as eficiências do sistema de irrigação localizada (Ea, Es, Ed, Epa, Pp, Gd e Gad);

2) Os modelos originados de regressão não linear não apresentaram diferenças entre os valores estimados dos parâmetros de eficiência de aplicação de água pelos modelos MPNL e MRNL, embora o modelo MRNL tenha apresentado melhor qualidade no ajuste aos dados observados;

3) A metodologia baseada nos modelos de regressão não linear (MPNL e MRNL) mostrou-se satisfatória e de simples execução na estimativa dos parâmetros de eficiência de aplicação da água do sistema de irrigação;

4) Os modelos propostos no trabalho são adequados para descrever a distribuição dos valores de lâmina ou volume de água aplicada fornecendo os parâmetros necessários para a avaliação de desempenho de sistemas de irrigação localizada.

\section{Referências}

ABNT - Associação Brasileira de Normas Técnicas. (1985). Sistema de irrigação localizada: avaliação do desempenho, 85 p.

Ailliot, P, \& Monbet, V. (2012). Markov-switching autoregressive models for wind time series. Environmental Modelling \& Software, $30,92-101$.

Alves, C. F. G., Lucio, J. C. B., Menezes, S. M., Almeida, R. S., Silva, F. B., \& Silva J. C. (2015). Avaliação de um sistema de irrigação por microaspersão na cultura do maracujá (Passiflora sp.). XXV CONIRD - Congresso Nacional de Irrigação e Drenagem, 1221-1226.

Anyoji, H., \& Wu, I. P. (1994). Normal Distribution Water Application for Drip Irrigation Schedules. Transactions of ASAE, 37(1), 159-164.

ASAE - American Society of Agricultural Engineers. (1996). Standard engineering practicesdata: EP458. Field evaluation of microirrigation systems. St. Joseph: ASAE, 972-797.

Barros, M. V. G. et al. (2012). Análise de dados em saúde. Midiograf, 2012.

Bernardo, S., Soares, A. A., \& Mantovani, E. C. (2006). Manual de irrigação. (8a ed.), UFV, 625p.

Burnham, K. P., \& Anderson, D. R. (2002). Model selection and multimodel inference: a pratical information-theoretic approach. Springer, 488p.

Bussab, W. de O., \& Morettin, P. A. Estatística básica. (6a ed.), Saraiva, 2010. 540p

Camargo, A. P. de, \& Sentelhas, P. C. (1997). Avaliação do desempenho de diferentes métodos de estimativa da evapotranspiração potencial no Estado de São Paulo, Brasil. Revista Brasileira de Agrometeorologia, 5(1), 89-97.

Capp, E., \& Nienov, O. H. (2020). Bioestatística quantitativa aplicada. Universidade Federal do Rio Grande do Sul, UFRGS, 260p.

Conceição, M. A. F. \& Coelho, R. D. (2003). Simulating wind effect on microsprinkler water distribution. Scientia Agricola, 60(2), 205-209.

Conceição, M. A. F., \& Coelho, R. D. (2003). Simulating wind effect on microsprinkler water distribution. Scientia Agricola, 60, $205-209$.

Cordão, M. A. (2019). Cultivo do maracujazeiro amarelo sob lâminas de irrigação e consórcio com feijão-caupi. Dissertação de Mestrado em Engenharia Agrícola - Universidade Federal de Campina Grande 57p. 
Cuenca, R. H. (1989). Irrigation System Design: Anengineering approach. 547p.

Elliot, R. L., Nelson, J. D., Lofts, J. C., \& Hart, W. E. (1980). Comparison of sprinkler uniformity models. Journal of Irrigation and Drainage Division, 106 (4), $321-330$.

Faccioli, G. G. (2002). Modelagem da uniformidade e da lâmina de irrigação na produtividade do feijoeiro. Tese de Doutorado em Engenharia Agrícola, Universidade Federal de Viçosa, UFLA, 205p.

Fernandes, D. Á, Araújo, M. M. V, \& Camili, E. C. (2015). Crescimento de plântulas de maracujazeiro-amarelo sob diferentes lâminas de irrigação e uso de hidrogel. Revista de Agricultura, 90(3), 229 -236.

Frizzone, J. A., Freitas, P. S., Rezende, R., \& Faria, Manoel A. (2012). Microirrigação: gotejamento e microaspersão. Eduem, 356p.

Harrell, F. E. (2015). General Aspects of Fitting Regression Models. In: Regression Modeling Strategies. Springer Series in Statistics. Cham: Springer International Publishing, 13-44.

Hartmann, M., Moala, F. A. \& Mendonça, M. A. (2011). Estudo das Precipitações Anuais Máximas em Presidente Prudente. Revista Brasileira de Meteorologia (Impresso), 24, 561-568.

Hund, E., Massart, D. L., \& Smeyers-Verbeke, J. (2002). Robust regression and outlier detection in the evaluation of robustness tests with different experimental designs. Analytica Chimica Acta, 463, 53-73.

Júnior, M. V., Rocha, J. P. A., Demontiêzo, F. L. L. Lima, L.S.S., Carvalho, C.M.C., \& Carvalho, L. L. S. (2016). Análise comparativa de metodologia de coleta de dados para avaliação de sistemas de irrigação localizada. Revista Brasileira de Agricultura Irrigada, 10(5), 965-975.

Karmeli, D. (1978). Estimating sprinkler distribution patterns using linear regression. Transactions of the American Society of Agricultural Engineers, 21(4), 682-686.

Keller, J., \& Bliesner, D. R. (1990). Sprinkle and trickle irrigation. von Nostrand Reinhold, 652p.

Keller, J., \& Karmeli, D. (1975). Trickle irrigation design. S.1: Rain Bird Sprinkler Manufacturing Corporation, 1975.133 p.

Levine, D. M., Berenson, M. L., \& Stephan, D. (2000). Estatística: Teoria e aplicações. LTC.

Lima, L. O., Oliveira, J. P. O., Almeida, R. R., Diniz, M. R. M., Miranda, M. S., \& Sousa, J. S. C. (2012). Estimativa da eficiência de um sistema de irrigação por microaspersão. In: VII CONNEPI - Congresso Norte Nordeste de Pesquisa e Inovação, 7, 2012, Palma - Tocatins. Anais...CONNEPI.

Maciel, L. F. V. (2019). Regressão linear múltipla na modelagem de resultados na National Basketball Association (NBA). Monografia - Bacharelado em Estatística, Universidade Federal de Uberlândia, , 52p.

Mantovani, E. C., Bernardo, S., \& Palaretti, L. F. (2009). Irrigação: princípios e métodos. (2a ed.), 355p.

Martín-Benito, J. M. T. (1993). La aplicación del agua el riego y su evaluación. In: Olalla Mañas, F.M.S. Agronomia del riego. Madri: Ediciones Mundi-Prensa, 615-694.

Martins, L. C. (2000). Relação entre poluição atmosférica e algumas doenças respiratórias em idosos: avaliação do rodízio de veículos no município de São Paulo. Dissertação de Mestrado em Ciências - Faculdade de Medicina, Universidade de São Paulo-USP, 97p.

Merrian, J. L., \& Keller, J. (1978). Farm irrigation system evaluation: A guide for management. Logan: Agricultural and Irrigation Engineering Department, Utah State University, 271p.

Monteiro, J., Tarjuelo, J. M., \& Carrión, P. S. (2001). Simulation model for sprinkler irrigation. Part II: Calibration and validation of the model. Irrigation Science, New York, 20(2), 85-98.

Neto, M. C. C. C., Nörenberg, B. G., Manke, E. B., Faria, L. C., Beskow, S., Colombo, A., Flores, J. H. N., Boeira, S. V., Vargas, M. M., \& Bruna Moreira Sell, B. M. (2012). Modelagem da lâmina de água aplicada por um linear móvel de irrigação equipado com dois modelos de aspersores. In: XXI ABRH - XXI Simpósio Brasileiro de Recursos Hídricos, 2015, Brasília-DF. Anais... Brasília: ABRH, 1-8.

Nóbrega, M. P. (2010). Estudo comparativo de gráficos de probabilidade normal para análise de experimentos fatoriais não replicados. Dissertação de Mestrado em Matemática Aplicada e Estatística, Universidade Federal do Rio Grande do Norte, 196p.

Oliveira, F. C. (2014). Produtividade da água no cultivo de brócolis de cabeça sob diferentes sistemas de irrigação. Dissertação de Mestrado em Engenharia Agrícola, Universidade Federal da Grande Dourado - UFGD, 59p.

Paulinho, M. A O., Figueiredo, F. P., Fernandes, R. C., Maia, J. T. L. S., Guilherme, D. O., \& Barbosa, F. S. (2009). Avaliação da uniformidade e eficiência de água em sistemas de irrigação por aspersão convencional. Revista Brasileira de Agricultura Irrigada, 3(2), 48-54.

Pizarro, F. (1996). Riego localizados de alta frecuencia. (2a ed.), Ediciones Mundi Prensa, 471 p.

Salomão, L. C. (2008). Uniformidade do sistema de irrigação. In: Souza. T. R., Villas Boas, R. L., Saad. J. C. C. Aspectos práticos da fertirrigação. Botucatu: FEPAF, cap. 3, 13-17.

Salomão, L. C. (2012). Calibração de tanques evaporímetros de baixo custo sob diferentes diâmetros em ambiente protegido. Tese doutorado, Universidade Estadual Paulista "Júlio De Mesquita Filho, UNESP, 74p.

Salomon, K. (1979). Manufacturing variation of trickle emitters. Transactions of the ASAE, St. Joseph, 22(5), 1034-1038. 
Research, Society and Development, v. 10, n. 7, e32610716566, 2021

(CC BY 4.0) | ISSN 2525-3409 | DOI: http://dx.doi.org/10.33448/rsd-v10i7.16566

Santos F. A. A et al. (2015). Avaliação do uso de dados de precipitação gerados pelo CPC/NCEP na modelagem hidrológica em uma região hidrográfica do rio Araguaia, Simpósio Brasileiro de Sensoriamento Remoto - SBSR, João Pessoa-PB, Brasil

Schmidt, C. M. C. (2003). Modelo de regressão de Poisson aplicado à área da saúde. Dissertação de Mestrado em Modelagem Matemática - Universidade Regional do Noroeste do Estado do Rio Grande do Sul98p.

Schons, R. L. (2010). Critérios para o aumento do índice de eficiência nos sistemas de irrigação tipo pivô central. Tese de Doutorado, Universidade Federal de Santa Maria (UFSM), Centro de Ciências Rurais, Programa de Pós-Graduação em Engenharia Agrícola, área de concentração em Engenharia de Água e Solo, $139 \mathrm{p}$.

Silva, E. M., Azevedo, J. A., \& Lima, J. E. F. W. (2002). Análise de desempenho da irrigação - Planaltina, DF. Embrapa Cerrados, 84p.- (Documentos / Embrapa Cerrados,

Silva, E. M., \& Hart, W. E. (1992). Modelo estatístico de distribuição de água infiltrada aplicado à irrigação deficiente. In: Congresso Nacional De Irrigação E Drenagem, $9^{\mathrm{a}}$., 1992, Fortaleza. Anais... Fortaleza: ABID, 1, 469-492.

Silva, E. M., Lima, J. E. F. W., \& Azevedo, J. A. (2009). Proposta e seleção de uma função polinomial para a avaliação de sistemas de irrigação. R. Bras. Eng. Agríc. Ambiental, 13(5), 509-515.

Silva, E. M., Lima, J. E. F. W., Azevedo, J. A., \& Rodrigues, L. N. (2004). Proposição de um modelo matemático para a avaliação do desempenho de sistemas de irrigação. Pesquisa Agropecuária Brasileira, 39, 741-748.

Silva, E. M., Lima, J. E. F. W., Rodrigues, L. N., \& Azevedo, J. A. (2006). Comparação de modelos matemáticos não-lineares empregados na análise de desempenho de sistemas de irrigação. Pesq. agropec. bras., Brasília, 41(6), 1049-1052.

Silva, E. M., Pereira, L. S., Ferreira, J. O. P., Lima, C. J. G. S., \& Silva, J. B. L. (2017). Avaliação de um sistema de irrigação por gotejamento em cultivo de quiabeiro. XLVI Congresso Brasileiro de Engenharia Agrícola - CONBEA 20173, , 1-4.

Silva, N. A. M., Lana, A. M. Q., \& Silva, F. F. (2011). Seleção e classificação multivariada de modelos de crescimento não lineares para bovinos Nelore. Arq. Bras. Med. Vet. Zootec., 63, 364-371.

Soccol, O. J., Ullmann, M. N., \& Frizzone, J. A. (2002). Análise de desempenho de uma subunidade de irrigação por gotejamento instalada em um pomar de macieira, Braz. arco. biol. technol. 45(4), 1 -9.

Souza, L. O. C., Mantovani, E. C. M., Soares, A. A., M. Ramos, M., \& Freitas, P. S. L. (2006). Avaliação de sistemas de irrigação por gotejamento, utilizados na cafeicultura. R. Bras. Eng. Agríc. Ambiental, 10(3) 541-548.

Warrick, A. W., Hart, W. E., \& Yatayew, M. (1889). Calculation of distribution and efficiency for nonuniform irrigation. Journal of Irrigation and Drainage Engineering, 115(4), 674-686.

Wu, I. P. (1995). Optimal scheduling and minimizing deep seepage in microirrigation. Transactions of the ASAE, 38(5), $1385-1392$. 